\title{
Plans and Preliminary Results of Fundamental Studies of Ice Crystal Icing Physics in the NASA Propulsion Systems Laboratory
}

\author{
Peter M. Struk ${ }^{1}$ \\ NASA Glenn Research Center, Cleveland, OH, 44135, USA \\ Jen-Ching Tsao ${ }^{2}$ and Tadas Bartkus ${ }^{3}$ \\ Ohio Aerospace Institute, Cleveland, Ohio, 44135, USA
}

\begin{abstract}
This paper describes plans and preliminary results for using the NASA Propulsion Systems Lab (PSL) to experimentally study the fundamental physics of ice-crystal ice accretion. Ice accretion due to the ingestion of ice-crystals is being attributed to numerous jet engine powerloss events. The NASA PSL is an altitude jet-engine test facility which has recently added a capability to inject ice particles into the flow. NASA is evaluating whether this facility, in addition to full-engine and motor-driven-rig tests, can be used for more fundamental iceaccretion studies that simulate the different mixed-phase icing conditions along the core flow passage of a turbo-fan engine compressor. The data from such fundamental accretion tests will be used to help develop and validate models of the accretion process. This paper describes the planned studies at PSL as well as some data from some preliminary testing performed in May 2015. This testing examined how a mixed-phase cloud could be generated at PSL using evaporative cooling in a warmer-than-freezing environment. Parameters such as total water content, plenum humidity, and spray bar air and water temperature were varied producing clouds ranging from fully-liquid to fully glaciated including a variety of mixed-phase conditions. Those conditions, along with a variety of test-section measurements, are presented together with images of observed ice accretions. A noteworthy observation from this testing, and similar to other tests, was that the measured temperature and humidity at the test section changed in such a way that the wet-bulb temperature remained nearly constant.
\end{abstract}

\section{Nomenclature}

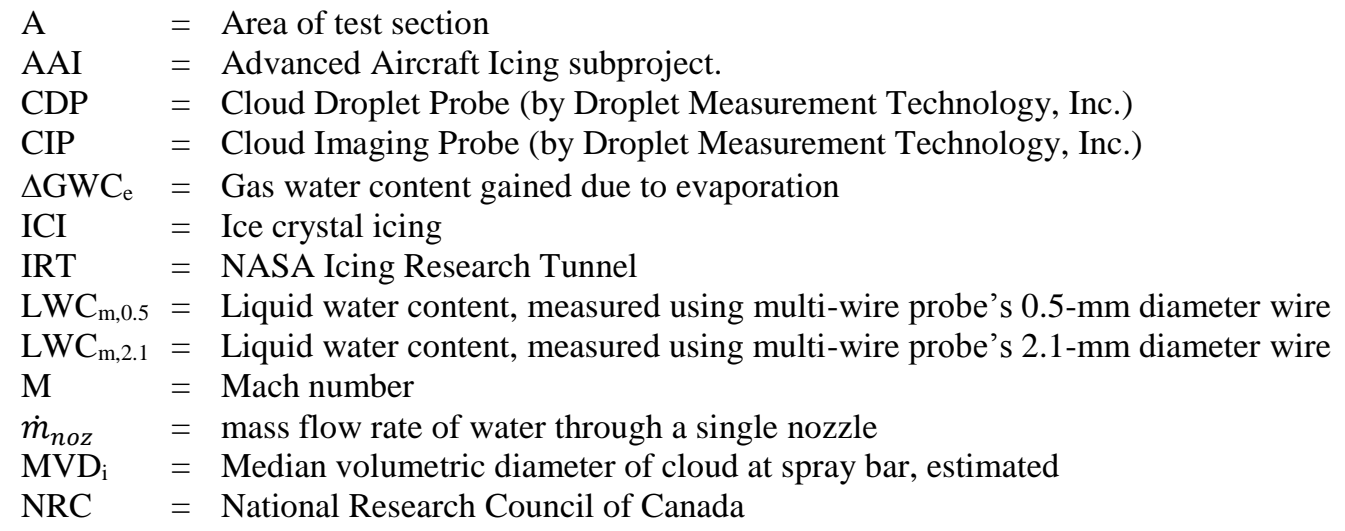

\footnotetext{
${ }^{1}$ Aerospace Engineer, Icing Branch, 21000 Brookpark Road, MS 11-2, AIAA Senior Member.

${ }^{2}$ Principal Research Scientist, Icing Branch, 21000 Brookpark Road, MS 11-2, AIAA Associate Fellow.

${ }^{3}$ Research Associate, Icing Branch, 21000 Brookpark Road, MS 110-3, AIAA Member.
} 

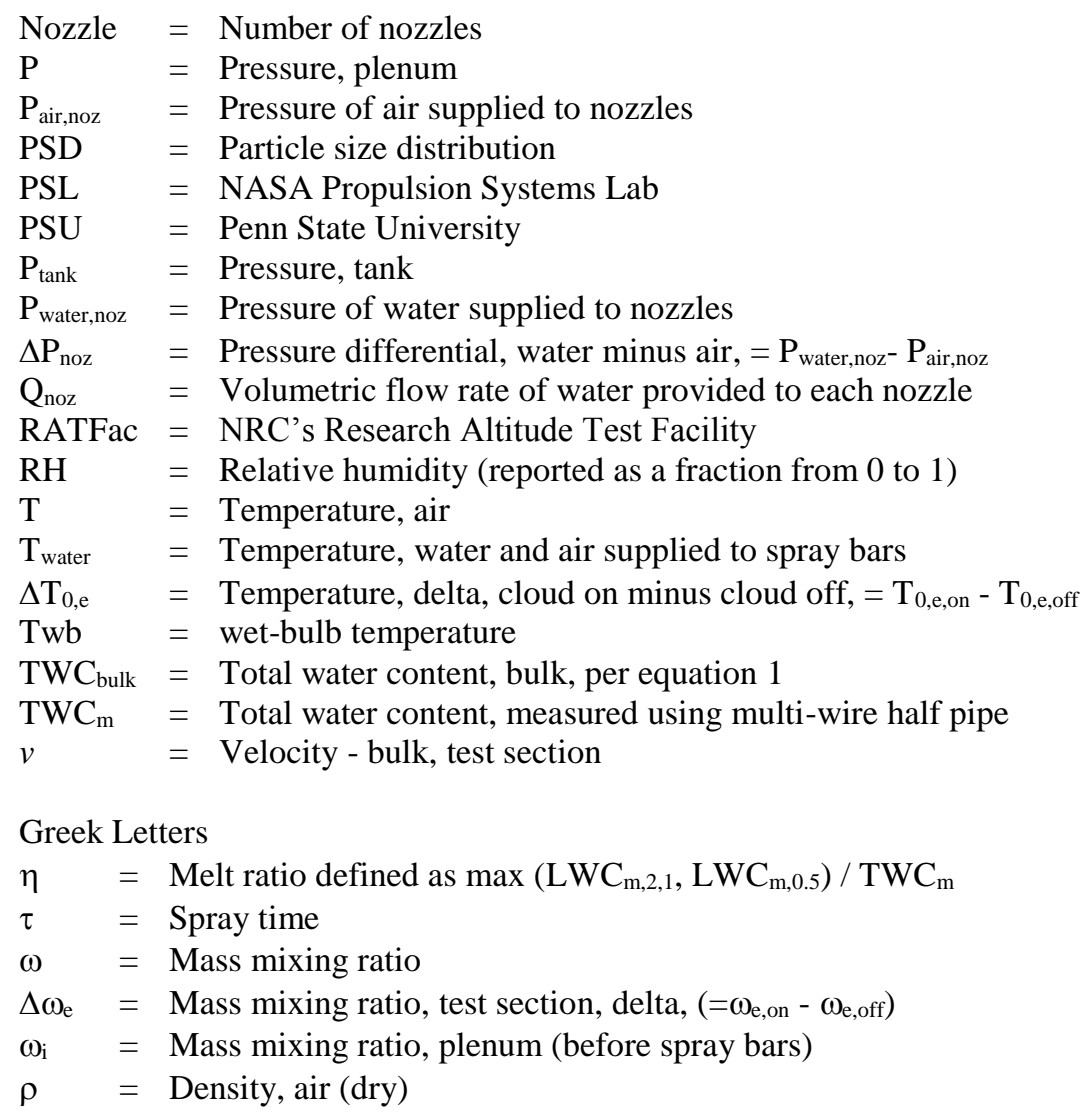

\section{Subscripts}

$0 \quad=\quad$ total or plenum conditions

$\mathrm{e} \quad=$ exit or test section (i.e. PSL station 1) conditions

$\mathrm{i}=$ inlet (at spray bars) condition

off $\quad=$ Cloud off measurement or calculation

on $\quad=$ Cloud on measurement or calculation

$\mathrm{s} \quad=$ static conditions

\section{Introduction}

$\mathrm{N}$ ASA is investigating the fundamental physical mechanisms of icing that occurs in core compressor regions of jet engines when ingesting ice crystals. The overarching goal of these tests is to improve understanding of the ice growth physics and expand engine aero-thermodynamic modeling capability to predictively assess the onset of icing in current and future $\mathrm{N}+2 / \mathrm{N}+3$ aircraft during flight operation. The investigations ultimately seek to answer two basic questions: (1) Under what conditions do ice-crystal ice accretions occur; and (2) is it feasible to duplicate the icecrystal accretion at a scaled condition? To answer these questions, it is necessary to understand the various underlying icing processes such as particle impact and breakup, phase change, accretion, and erosion. Furthermore, it is critical to quantify key icing parameters at the accretion site such as the total water content, fraction of liquid to total water content, particle size and phase distribution, and aero-thermal conditions such as pressure, velocity, temperature, and humidity.

The NASA Propulsions Systems Lab (PSL) has recently added a capability to inject ice particles into an operating jet-engine ${ }^{1}$. To date, several successful test programs using both jet engines and test rigs have been performed at the facility offering insight into the engine ice-crystal icing ${ }^{2-4}$. At PSL, the ice particles are generated using liquid-water spray nozzles which are injected upstream in a plenum area. The water droplets freeze prior to reaching the engine or rig due to a combination of convective and evaporative cooling. Once inside the jet-engine, the ice particles are 
presumed to break-apart and begin to melt generating a mixed-phase condition before reaching the accretion site in the compressor.

Because it is difficult to study the physics of such accretions directly inside the engine, NASA is evaluating whether this facility, in addition to full-engine and motor-driven-rig tests, can be used for more fundamental iceaccretion studies. These fundamental studies seek to simulate the internal engine conditions leading to icing but in an external flow environment. This necessitates matching the internal environment at the accretion site of the jet engine including the (1) wet-bulb temperature, (2) particle size distribution, and (3) melted portion of incoming ice. An ultimate objective of this research is to develop the capability to generate a prescribed mixed-phase condition at the test section for fundamental ice-crystal icing research.

Earlier investigations, conducted by NASA jointly with the National Research Council of Canada (NRC) at the NRC Research Altitude Test Facility (RATFac), identified that the local wet-bulb temperature, particularly near freezing, played an important role on accretion ${ }^{5-7}$. At higher altitude (i.e. decreased pressure) evaporative cooling is enhanced and the wet-bulb temperature becomes colder. In addition, the rapid temperature rise in the compressor region of a jet engine drops the local relative humidity further enhancing evaporative cooling. This necessitated the addition of measuring and controlling the local humidity as a key parameter in engine ice-crystal icing tests which now occurs in almost all such testing.

Ice crystal ingested from the atmosphere likely break apart due to impacts with rotating and static surfaces inside the engine. Various studies are underway ${ }^{8-10}$ suggesting that particles can catastrophically break apart with impacts at flight speeds. However, no one has yet measured the particle breakup inside a jet engine although studies ${ }^{11}$ have begun to estimate such breakup based on these fundamental tests. Furthermore, no one has yet directly compared the difference in accreted ice formed with ingested natural ice crystals and those produces in ground facilities, although initial tests at PSL suggest that engine response is similar in both flight and ground tests ${ }^{2}$. The RATFac uses an ice grinding technique to generate an ice crystal cloud with a MMD between 45 - and $200-\mu \mathrm{m}^{12,13}$. The spray bar system at PSL is able to generate clouds with particle size distributions (PSD) down to approximately $15-\mu \mathrm{m}{ }^{14}$ and one aspect of the present testing at PSL is to explore ice crystal ice accretions at these smaller PSDs.

Once inside the jet engine, the ice begins to melt due the warmer-than-freezing environment. At RATFac, the particles are injected directly into a warm environment where they begin to partially melt generating a mixed phase condition. In these tests, the smaller particles will melt first with the larger particles remaining partially solid until reaching the accretion site. The current PSL testing will examine a partial freeze-out technique to generate the mixed phase. The particles begin as liquid droplets and subsequently cool and evaporate as they flow towards the test section with the smaller particles freezing first and the larger droplets remaining partially liquid until reaching the accretion site. A detailed description and model of this process can be found elsewhere [REF]. An objective of the studies at PSL will be to ultimately compare ice accretions from both the RATFac and PSL to see how much the method used to generate the mixed-phase conditions affects the ice accretion characteristics. Furthermore, future tests at PSL might seek alternative ways to generate the mixed phase including adding heat to the flow to partially melt a completely glaciated ice-particle cloud.

\section{Overview of Testing Plans}

NASA's efforts in fundamental ice crystal icing (ICI) research started in 2009 under the Atmospheric Environments Safety Technologies Project ${ }^{15}$ and continues through today. During this time period, a NASA and NRC collaboration produced several papers on the topic of fundamental ICI research ${ }^{7,16-19}$. Other efforts during this time period related to the fundamentals of ICI include work on ice particle impact physics at NASA ${ }^{20}$, Penn State University $(\mathrm{PSU})^{21}$, and a collaboration with PSU and the John Hopkins Universities Applied Physics Lab ${ }^{8}$. In 2015, the NASA engine icing work was transitioned to NASA's Advance Air Transport Technology Project under a new subproject called Advanced Aircraft Icing (AAI). At its highest level, the AAI project seeks to expand engine aerothermodynamic modeling capability to predictively assess the onset of icing in current and future $(\mathrm{N}+2 / \mathrm{N}+3)$ aircraft during flight operation. Key enablers for this modelling capability are fundamental experiments to understand ICI physics that determine the conditions favorable for ice accretion and the rate of ice growth.

Starting in 2015 and continuing for the next five years, the NASA AAI subproject has conducted tests and is planning future tests at PSL to support fundamental ICI research. A preliminary 2-day test effort occurred in May 2015 and is the topic of this paper. The goals of the May 2015 tests were to gather initial data on controlling the mixed-phase at the test section and perform some limited characterization of the aero-thermal conditions and cloud. The first full fundamental ICI test was a 2-week effort and occurred in March 2016 but results from that test were not available in time to include in this paper and will be reported at a later date. The primary goals of the March 2016 
tests were to (1) evaluate the ability of controlling the mixed-phase at the test section (2) generate 2D ice shapes profiles on a NACA 0012 airfoil suitable for comparison with ice accretion models, and (3) characterize both the aerothermal conditions and cloud (e.g. PSD, water content, and uniformity).

The plans for the future tests are being developed and are subject to change. At this time, the notional plans for the $2^{\text {nd }}$ through the $4^{\text {th }}$ fundamental ICI tests are as follows. The $2^{\text {nd }}$ fundamental ICI test seeks to use the data gathered from the $1^{\text {st }}$ test and complementary modelling efforts ${ }^{22}$ to demonstrate the ability to prescribe a particular ICI condition at the test section. Furthermore, ice shapes will be generated on a NACA 0012 airfoil during both the $1^{\text {st }}$ and $2^{\text {nd }}$ test which are intended to help further develop and validate LEWICE models ${ }^{23,24}$ of the accretion process. For the third fundamental test, NASA is considering using an s-duct or other engine geometry to generate a more representative ice accretion as seen in recent engine testing ${ }^{4}$. The purpose of such tests is to help bridge the gap between ICI accretions observed on simpler 2D shapes such as airfoils to the more complex 3D ice shapes seen in engine testing. The data will ideally be used to help develop 3D ice accretions codes such as LEWICE3D. Finally, the $4^{\text {th }}$ fundamental ICI test is intended to evaluate scaling laws ${ }^{18,25}$ using the NACA 0012 airfoil similar in procedure to tests 1 and 2.

\section{Experiment Description - Preliminary Testing}

In May 2015, two days of testing occurred at PSL supporting NASA's fundamental ICI research. The goal for these two days was to achieve a range of mixed-phase conditions by examining various aero-thermal parameters and spray bar conditions. This section describes the experimental configuration and conditions tested.

\section{A. PSL Configuration}

For these tests, PSL was configured as a contracting duct with a 27:1 area ratio terminating in a 36 " diameter free jet. The geometry of the tunnel is shown in Figure 1 with the distance from the spray bars to the test section being approximately 8.7 meters with the last 2.16 meters being constant area. The test section, also referred to as station 1 , is the exit plane of the free jet. For the testing that took place in May 2015, several instruments were placed at or near the test section as shown in Figure 2. This configuration was used to measure the ratio of liquid to total water content (i.e. the melt ratio), total air temperature, and humidity. The tests examined techniques, using a rearward facing inlet, to take uncontaminated measurements of air temperature and humidity in the presence of a cloud. For these preliminary tests, a camera imaged the leading edge of the temperature and humidity inlet in order to detect any ice accretion, providing a secondary indication of the presence of mixed phase. Each of these measurements is further discussed in the sections below.

Regarding nomenclature, parameters with the subscript i (i.e. inlet) denote measurements or calculations from the plenum while those using the subscript e (i.e. exit) denote the test section. The subscripts 0 and s denote total or static conditions, respectively. Furthermore, the subscripts "on" and "off" refer to measurements (or calculations using measurements) with the cloud on or off, respectively.

\section{B. Spray settings}

Each test was set to a bulk total water content $\left(\mathrm{TWC}_{\text {bulk }}\right)$ at the test section calculated using equation 1 below. In this equation $\dot{m}_{n o z}$ is the mass flow rate through a single nozzle, Nozzles is the number of spray nozzles used to generate the cloud, $v_{\mathrm{e}}$ is the calculated flow velocity at the test section, and $\mathrm{A}$ is the cloud effective area which is assumed to be a 36 " diameter circle during these tests. $\mathrm{TWC}_{\text {bulk }}$ assumes that all the injected water is uniformly distributed across the section. However, a portion of the water does evaporate before it reaches the test section and the water droplets are not uniformily distributed. The actual TWC wasmeasured during the testing using the SEA multi-wire probe. During the March 2016 testing, TWC measurements were also made using the Isokinetic Probe 2 (IKP2) and those values may replace the values measured by the multi-wire probe at a later date.

$$
T W C_{\text {bulk }}=\frac{(\text { Nozzles }) \dot{m}_{n o z}}{v_{e} A}
$$

The PSL spray bars have the same types of nozzles as installed in the NASA Icing Research Tunnel (IRT). This includes both the standard and modified nozzles ${ }^{1}$. All tests reported in this paper used the modified nozzles. During these tests, the particle size distribution (PSD) of the spray was estimated using IRT values ${ }^{26}$ using the supplied air and water pressures (values listed in the appendix). Those values came from extensive testing at the test section of 
the IRT. The particle MVDs reported in the main body of this paper are target values. The appendix list the values from the calculator using the actual measured nozzle pressures during the tests.

At IRT, it is assumed that only a small amount of evaporation occurs between the spray bar and the test section. As a result, an approximation is made during these tests that the PSD at the PSL spray bars is approximately the same value as the IRT values at the test section. However, the PSL droplets do evaporate as they flow from the spray bars to the test section. Furthermore, the rates of evaporation are expected to vary with different test conditions such as temperature, pressure, and local humidity resulting in different particle size distribution for the same spray bar settings. It is a goal of this research to have a well characterized PSD for each conditions tested. PSL currently uses combined data from the Cloud Droplet Probe (CDP) and Cloud Imaging Probe (CIP) manufactured by Droplet Measurement Technologies. During this preliminary test, there was not an opportunity to take PSD measurements using these instruments. However, some exploratory research tests did occur using particle measurements probes being developed by Artium for application in mixed-phase condition and will be reported at a later time. Furthermore, test time was dedicated during the March 2016 testing for PSD measurements using the CDP and CIP and will be reported at a later date.

The water and air temperatures provided to the spray bars at PSL can be varied from approximately 45 to $180^{\circ} \mathrm{F}$. For the lower temperatures, the water is cooled using a glycol heat exchanger. An electric generator is used to heat the water for warmer temperatures. Further details on the PSL system can be found elsewhere ${ }^{1}$. For all of the tests, the air and water temperatures were set to the same value although the system does support setting the air and water to different temperatures. The majority of the cases for this preliminary test used an air and water temperature of 45 ${ }^{\circ} \mathrm{F}$. However, several tests were run at 100 and $180^{\circ} \mathrm{F}$ to examine the effect of air and water temperature on the melt ratio. Finally, the spray bars have a supplemental cooling air system which was included in the original PSL spray bar design to help ensure particle freezeout, should it be required. The supplemental cooling air system was not used during the preliminary testing but was used during the March 2016 tests.

Finally, PSL has the capability to use either de-ionized or city water. City water was used for the present tests as it is expected to help promote freezeout of the cloud.

\section{Multi-wire probe}

The total and liquid water contents at the test section are measured using the SEA multi-wire probe ${ }^{27}$. The total water content, reported as $\mathrm{TWC}_{\mathrm{m}}$, is measured using a hot-wire element with a half-pipe cross section where the concave portion is facing the incoming flow. A basic premise for the half-pipe element is that it captures and completely vaporizes all of the incoming ice particles and water droplets. The power required to maintain the element at temperature is related to the impinging water and ice. Previous studies in ice-crystals ${ }^{12,18,28}$ have measured values lower than the expected values of TWC. This behavior is likely due to ice-particle splashing, bouncing, or otherwise flowing away prior to being vaporized by the element.

The LWC is measured by two heated elements with a cylindrical cross section of 0.5 and $2.1 \mathrm{~mm}$ in diameter. Measurements from those elements are denoted as $\mathrm{LWC}_{\mathrm{m}, 0.5}$ and $\mathrm{LWC}_{\mathrm{m}, 2.1}$, respectively. The power required to maintain the element temperature is related to the impinging liquid water assuming that all LWC that contacts the wire evaporates. Data from the development of the SEA multi-wire probe ${ }^{27}$ suggests that the different diameter cylinders, just as with the TWC measurement, do not respond identically to liquid clouds of different MVD. In fact, the original intent of the multiple-diameter cylinders was to discriminate between clouds of different droplet sizes owing to the different collection efficiencies of the cylindrical wires. In pure ice-crystal conditions, both manufacturer testing as reported in the owner's manual and in other studies ${ }^{18}$ have indicated that the LWC elements have a false response to the presence of ice crystals. This is expected as some of the impinging ice would melt and cool the heated wire.

In mixed-phase, the signal measured by each of the hot-wire elements is a combination of liquid water and ice particles. To estimate the actual LWC and IWC from measurements by the SEA elements, an analysis method has been proposed ${ }^{29}$ in which each specific water contribution is adjusted for collection efficiency, splash loss, ice response, or false response, as required. However, the present dataset has not yet been adjusted for these factors since further testing is required to determine all of the correction factors. As such, the raw measurements directly from the probe are reported. The melt ratio is reported as the maximum LWC reading from either the 0.5 or $2.1 \mathrm{~mm}$ wire divided by $\mathrm{TWC}_{\mathrm{m}}$.

\section{Humidity control and measurement system}

The PSL varies the humidity at the test section by combining inlet air with steam injection. The humidity is measured using a water vapor sensor system. These components are described further below and in another referece ${ }^{1}$. 


\section{Inlet Air}

The Propulsion Systems Laboratory (PSL) uses externally compressed air as the inlet air (also called combustion air when connecting to an engine) to conduct altitude simulation testing in two separate test cells ${ }^{30}$. The incoming inlet air passes through a desiccant drying bed to remove the majority of water vapor content. Typical incoming dew point for PSL inlet air is $-80 \mathrm{~F}$. PSL has the capability to increase the water vapor content of the inlet air once it has entered the facility. This is accomplished via a steam injection system.

\section{Steam Injection System}

A steam injection system is installed physically near to where inlet air enters the facility. The combined inlet air and steam then travels approximately 150 feet to the test cell. Prior to entering the test cell the inlet air passes through a large cross sectional area chamber, or plenum, where Mach number is approximately 0.02. A water vapor measurement system is used to monitor the water vapor content of the inlet air inside the plenum. This allows researchers to test at a desired water vapor content for the inlet air.

\section{Water Vapor Sensor}

PSL uses a water vapor sensor (Model WVSS-II by Spectra Sensors) that employs a tunable diode laser absorption spectroscopy methodology to measure the water vapor content of a continuous flow sample of plenum air through the measurement cell. The continuous sample is extracted from the plenum via a vacuum driven flow control system connected to the exhaust side of the sensor. The volume flow rate of the continuous sample is controlled to typical values between 5-10 liters per minute through an approximately 20 foot, $1 / 2$ inch diameter line.

A duplicate Spectra Sensor system was used to measure the humidity at the test section where the flow was extracted through a rearward facing inlet as seen in Figure 2. A rearward facing inlet was used to prevent water and ice from being ingested into the system although the effectiveness of this method is still being evaluated as discussed below. For the low pressure test points (6.5 psia) presented in this paper, the flow rate through the spectra sensor dropped to approximately 2.7 liters per minute. This reduction was due to the flow blockage of the RTD wire embedded inside the rearward facing inlet. However, separate tests with the Spectra Sensor at similar flow rates did not produce an appreciable difference in the humidity measurement.

Representative humidity data is shown in Figure 3 for two tests. For test 677 (Figure 3A), the pre-spray humidity in the plenum and test section match almost exactly as expected. For case 676 (Figure 3B), the test section humidity is slightly larger than in the plenum. This small variation may be due to the presence of ice on the inlet. Examples of ice on the inlet can be seem in Figures 4-7. Prior to starting test 676, the probe was not deiced due to time constraints and that ice may have been sublimating causing the small bias. During the spray, the humidity at the test section increased rapidly and generally stabilized within 30 seconds. Typically, the humidity remained roughly constant during the spray (e.g. Figure 3A) or showed a small increase (e.g. Figure 3B). On occasion, the test section humidity suddenly grew rapidly mid spray. Such results are indicative of possible water contamination in the humidity system and were not included in the presented data. Another observation from the test section humidity data was that it did not always immediately return to the pre-spray values after completion of the spray (see $\omega_{\mathrm{e}}$ in Figure $3 \mathrm{~B}$ ). This behavior also may be due to the presence of ice on the probe or other possible contamination in the system. The humidity data presented in this paper should be understood to have uncertainty biases that are not completely characterized.

\section{E. Temperature measurements}

The total temperature is measured both at the plenum and at the test section. Multiple thermocouples are used to measure temperature in the plenum upstream of the spray bars which are then averaged into a single value. At the test section, the air temperature is measured inside a rearward facing inlet (see Figure 2) using a resistance temperature detector (RTD). The RTD is placed inside the rearward facing inlet to prevent measurement contamination from impinging water and ice particles. Also, the RTD is not in any direct thermal contact with surrounding metal to minimize any conduction biases. A small suction flow is induced in the probe to improve the probes response to changes in air temperature. The temperature measurements have been calibrated to read total temperature given the flow Mach number. The static temperature is then calculated from the total temperature using isentropic relations and the Mach number at the test section.

Figures 3A and 3B show sample total air-temperature measurements at the test section for tests 677 and 676, respectively. As seen by the data in the appendix, the total temperature measurements in the plenum and at the test section generally agree to within a degree or better prior to initiating the spray, as expected, although there are a a few outlying test points (especially higher speed points). After the spray is turned on, all tests presented shows a drop in 
air temperature. For test 677 (Figure 3A), the temperature drop was approximately $3^{\circ} \mathrm{F}$ while the drop was almost $4^{\circ} \mathrm{F}$ for test 676 (Figure 3B). For both cases, it took approximately 2 minutes for the temperature to reach a new steady-state value. It is believed that this long time response is due to the thermal inertia of the reward facing probe. The air temperature, which is thought to change almost instantaneously with the addition of the spray, is warmed as it flows along the probe just prior to being ingested into the reward facing inlet where the measurement is made. The probe body eventually reaches a new steady-state temperature which then allows for the air temperature to be measured. Further work is underway investigating the operation of this probe and the influence of the probe body and any contamination such as water and ice on the probe. As such and similar to the humidity measurement, the temperature data from this probe should be understood to have uncertainty biases that are not yet well characterized.

\section{F. Ice accretion imaging}

Video cameras were positioned to view the side and top of the rearward facing inlet. The cameras and corresponding lighting were located outside of the flow at the exit of the free jet. These cameras provided images of ice accretion on the inlet as seen in Figures 4 to 8 . The inlet, when viewed from the top, had an airfoil shape and ice accretions from this view are similar to an ice tracing (see bottom images of Figures 4-8). When viewed from the side, the spanwise variation of ice could be seen along the inlet (see top images of Figures 4-8).

\section{G. Test conditions \& wet-bulb temperature}

With regard to test procedures, the pressures in the facility were set first followed by the total temperature. Once the temperature was steady, the humidity in the plenum was set. The spray bar temperatures and pressures were set to their target values once the facility pressures were set. Prior to the spray, at least 30 seconds of all data was recorded with the average of that data reported in this paper as the measured cloud-off condition. Data was recorded throughout the entire spray with the last 30-seconds averaged and reported as the measured cloud-on condition.

The wet-bulb temperatures reported in this paper were calculated using the method described in Veres et al. ${ }^{31}$. Different wet-bulb temperatures are reported in this paper based on location, total or static conditions, and whether using cloud-off or cloud-on measurements. The subscript notation described previously describes the parameters used in the calculation. For example, the total wet-bulb calculated at the test section with the cloud on is denoted as $T w b_{0, e, o n}$ and is calculated using total temperature (using the RTD measurement with the cloud on corrected to total temperature), mass-mixing ratio (measured with the cloud on), and total pressure. Static wet-bulb are calculated similarly but use static pressure, mass mixing ratio, and static temperature using either cloud on or off conditions, as denoted by the subscripts. The total wet-bulb can represent the surface temperature in a stagnation region while the static wet-bulb can represents the steady-state particle temperature according to modelling ${ }^{16}$.

\section{Results}

The focus of the May 2015 testing was to examine PSL facility parameters and observe their effect on the melt ratio of the cloud at the test section. Three primary parameters were examined: bulk TWC, plenum humidity, and spray bar air and water temperature. Each of these variations are discussed in separate sections below. Within these sets of results, target particle size was also varied between a smaller, nominally $15-\mu \mathrm{m} \mathrm{MVD}$, and larger value of $40-\mu \mathrm{m} \mathrm{MVD}_{\mathrm{i}}$. For bulk TWC and spray bar temperature tests, the wet-bulb temperature at the test section was also varied between a warmer and colder condition.

The primary measurements examined were the centerline total water content and melt ratio measured by the multiwire probe. In addition, the humidity and temperature was measured approximately 9 inches from the centerline to compare cloud off versus cloud on values. As discussed previously, the humidity and temperature measurements were designed to not be contaminated by water or ice impingement on the sensor areas. Finally, any ice accretion observed on the temperature and humidity probe was also noted and recorded on video. Figures 4-7 contain images from two different video views including both a span-wise view (top images in Figures) and a side-profile view (bottom images in Figures). The ice accretions shown are images taken within a few seconds of the end of the spray.

Tables 1 through 4 show target facility conditions (top) and primary measurements (bottom). The actual facility measured conditions for each test point are listed in the appendix. During a given test point, the facility generally maintained pressures and temperatures to approximately \pm .05 psia and $\pm 1{ }^{\circ} \mathrm{F}$, respectively. For relative humidity, the plenum set point was maintained $\pm 1 \%$. The cloud particle size distributions are reported as IRT values, denoted as $M V D_{i}$, and are currently approximated to be a representative value at the spray bars. The actual MVDs at the test section of PSL will be larger than the IRT values due to evaporation of the smaller particles. Actual particle size 
measurements were not taken during this set of tests. Finally, the data in Tables 1-4 is reported to two significant figures. The appendix list the measured values at higher resolution and includes additional parameters not shown in Tables 1-4.

\section{A. TWC Sweeps}

The TWC was varied during different tests with other conditions held approximately constant. These variations, or sweeps, were performed at two different wet-bulb temperatures and two particle size distributions. For each sweep, the bulk TWC was varied from approximately 0.5 to $5 \mathrm{~g} / \mathrm{m}^{3}$. The first sweeps, shown in Table 1, used the smaller particle size of $\mathrm{MVD}_{\mathrm{i}} \sim 15 \mu \mathrm{m}$ except for the largest TWC values which had a $\mathrm{MVD}_{\mathrm{i}}$ of $\sim 19 \mu \mathrm{m}$ due to spray bar limitations. TWC Sweeps 1 and 2 were performed at two different static wet-bulb temperatures of $\mathrm{Twb}_{\mathrm{s}, \mathrm{e}, \mathrm{off}}=25$ and $19^{\circ} \mathrm{F}$, respectively. Hereafter, these wet-bulb temperatures are referred to as the warmer and colder Twb. The wetbulb temperature change between TWC Sweeps 1 and 2 was due to reducing the static pressure from 12.1 to 6.2 psia. For TWC Sweeps 3 and 4, which used the larger particle size of $M V D_{i} \sim 40-\mu \mathrm{m}$, a change in the facility total temperature produced the wet-bulb variation.

\section{TWC Sweep 1 and 2: Smaller Particle Size, $T w b_{s, e, o f f}=25^{\circ} \mathrm{F}$ and $20^{\circ} \mathrm{F}$.}

Ice accretion was observed for only two cases in these sweeps, Test \# 666 and 663 as seen in Figure 4, both of which occurred at the warmer $\mathrm{Twb}_{\mathrm{s}, \mathrm{e}, \mathrm{off}}$ of $25^{\circ} \mathrm{F}$. The green light visible in some of the ice accretion images is from the PDI laser and had the unintended benefit of better illuminating the leading edge of the ice shape profile as seen in the top view image of Test \#663. Test \#666 produced an ice accretion with a glazy, clear appearance while Test \#663 had a rime-like, opaque appearance. Furthermore, the ice shape in Test \#666, when looking at the side-profile view, appeared to be more conformed to the leading edge of the probe on which it accreted while Test \#663 had a sharp peak-shaped profile. It was not immediately clear why ice accretion was seen only at the lowest and highest TWC for this sweep so a detailed look at the test conditions was in order.

Examination of Table 1 showed the following general trends:

- The measured total water content, $\mathrm{TWC}_{\mathrm{m}}$, at the tunnel center was consistently smaller than the bulk injected value, $\mathrm{TWC}_{\text {bulk. }}$.

- As $\mathrm{TWC}_{\text {bulk }}$ increased, so did the measured specific humidity at the test section, $\Delta \omega_{\mathrm{e}}$. The increase in humidity appeared to taper above roughly $2 \mathrm{~g} / \mathrm{m}^{3}$ for the warmer Twb case while the increase was monotonic for the colder Twb case.

- As TWC bulk increased, the measured air temperature decreased. Again, the temperature decrease tapered (in fact began to slightly increase) above roughly $2 \mathrm{~g} / \mathrm{m}^{3}$ for the warmer Twb case while the decrease was monotonic was the colder Twb case.

- The calculated Twb using the cloud on temperature and humidity generally matched the dry, cloud off, Twb. That is $T w b_{0, e, o f f}$ generally equaled $T w b_{0, e, o n}$ as was the same for $T w b_{s, e, o f f}$ and $T w b_{s, e, o n}$. The agreement lessened as the $\mathrm{TWC}_{\text {bulk }}$ increased.

Comparing Test \#666 and 667, where $\mathrm{TWC}_{\text {bulk }}$ varied from 0.55 to 1.0 , showed that the melt ratio, $\eta_{\mathrm{e}}$, decreased from 79 to $16 \%$. Assuming other variables were equal, this indicates that a majority of the cloud froze out simply by increasing the TWC. Test 666 produced a clear ice shape suggesting that the water was supercooled while test 667

did not produce an accretion. Curiously, the measured $\mathrm{TWC}_{\mathrm{m}}$ was approximately the same for both of these cases suggesting that more of the water evaporated for Test \#667 which is corroborated by the measured humidity increase, $\Delta \omega_{\mathrm{e}}$, for this case. Further work is required to explain why test 666 contained more liquid and 667 was mostly glaciated.

Test points 663 and 681, which both had a $\mathrm{TWC}_{\text {bulk }}$ of $4.9 \mathrm{~g} / \mathrm{m} 3$, also showed a transition from ice accretion to no accretion. These cases shared a similar initial drop size distributions but which was larger than the other cases in Table 1 . The measured melt ratio of $8 \%$ for Test \#681 suggests a fully glaciated cloud; again the small liquid fraction is likely a false sensor response to ice crystals as explained in the multi-wire probe section above. The warmer conditions of Test \#663 resulted in more liquid water with a melt ratio of roughly 20\%, a mixed-phase condition but mostly ice. As a result, the ice accretion showed characteristics of erosion (i.e. the peak-shaped profile as seen in the side-profile view of Figure 4) due to presence of ice crystals. Test \#663 was not directly compared to other test points in its temperature group (test points 666, 667, 665, and 664) since the initial drop sizes were slightly different. Based on IRT calibration data, the largest particle in 15- $\mu \mathrm{m}$ MVD cloud is 50- $\mu \mathrm{m}$. However, a 20- $\mu \mathrm{m}$ MVD cloud has a small fraction of particles above $200-\mu \mathrm{m}^{26}$. It is these larger particles which are speculated to not completely freeze resulting in the mixed phase. 


\section{TWC Sweep $3 \& 4$ : Larger Particle Size, $T w b, s=23^{\circ} \mathrm{F}$ and $20^{\circ} \mathrm{F}$.}

Ice accretion was observed for all 8 test points in sweeps shown in Table 2 with 4 of those accretions shown in Figure 5. The images in this figure show the accretion at the end of the spray that began with an ice-free probe. Due to limited testing time, the probe was not deiced between all test points. The test points not shown in Figure 5 were cases where the probe was not deiced initially. For these cases, ice accretion was evident by comparing the ice thickness before and after the spray. Test points 670,671, and 677 produced similar looking ice accretions with a glazy, clear appearance which conformed to the leading edge of the probe. These cases had a higher melt ratio of approximately $70 \%$. Test $\# 674$, which had a rime, opaque appearance with a peaky shape, had a lower melt ratio of $20 \%$.

Examination of Table 2 showed the following general trends:

- The measured total water content, TWCm, was consistently larger than the bulk injected value, $\mathrm{TWC}_{\text {bulk }}$. In many cases, the measured values was almost double the bulk injected value. The larger measured values of water content may be a results of a non-uniform cloud and needs to be further explored.

- As $\mathrm{TWC}_{\text {bulk }}$ increased, so did the measured specific humidity at the test section, $\Delta \omega_{\mathrm{e}}$. Different than the TWC sweep in Table 1, the increase in humidity was monotonic for both Twb conditions.

- As $\mathrm{TWC}_{\text {bulk }}$ increased, the measured air temperature decreased. The temperature decrease was generally monotonic for both Twb cases with the exception of Test \#675.

- Similar to the TWC sweeps shown in Table 1, the calculated Twb using the measured temperature and humidity at the test section generally matched the dry, cloud off value with the agreement lessening with increased $\mathrm{TWC}_{\text {bulk. }}$.

- $\quad$ As TWC $_{\text {bulk }}$ increased, there seemed to be a step change in melt ratio for both TWC sweeps in Table 2. When the $\mathrm{TWC}_{\text {bulk }}$ increased from 1.4 to $2.3 \mathrm{~g} / \mathrm{m} 3$, the melt ratio changed from $\sim 70 \%$ to $\sim 20$ to $25 \%$. After examining all of the data for these cases, it was not immediately clear why there was a transition such a drastic change in melt ratio when increasing TWC.

\section{B. Relative Humidity Sweeps}

In this set of tests, the plenum relative humidity was varied to observe its effect on melt ratio at the test section (Table 3). The plenum humidity ranged from 10 to $50 \%$ with a single point in between. Sweeps were performed at

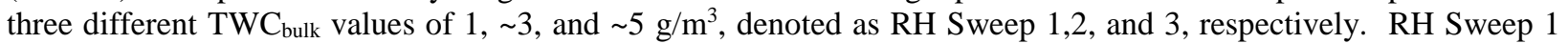
used an $\mathrm{MVD}_{\mathrm{i}}$ of 15 microns while RH Sweeps 2 and 3 used an MVD $\mathrm{D}_{\mathrm{i}}$ of 19 microns. Also, RH sweep 2 occurred at a flow speed of $135 \mathrm{~m} / \mathrm{s}$.

Figure 6 shows images of ice accretion from the RH sweeps - only two cases produced an ice accretion, tests 685 and 682. The ice accretion produced during test 685 (which has a greater water loading) was larger compared to 682 . In addition, the accretion for Test \#685 showed some characteristics of erosion with a somewhat peak-shaped appearance from the side-profile view. The accretion in Test \#682 was very clear and conformal to the leading edge of the probe.

Examination of Table 3 showed the following general trends:

- $\quad$ As $\mathrm{RH}_{0, \mathrm{i}}$ increased, the measured TWCm increased indicating that less of the cloud was evaporating, as expected. For Test \#667, the TWCm was smaller than TWC bulk. For tests 685 and 686, the TWCm was larger than $\mathrm{TWC}_{\text {bulk. }}$ In all the other cases, $\mathrm{TWCm}$ was approximately the same as $\mathrm{TWC}_{\text {bulk. }}$ The differences in measured water content may be a result of a non-uniform cloud and needs to be further explored.

- As $\mathrm{RH}_{0, \mathrm{i}}$ increased, the amount of water evaporation decreased as seen by examining the specific humidity change, $\Delta \omega_{\mathrm{e}}$. at the test section.

- $\quad$ As $\mathrm{RH}_{0, \mathrm{i}}$ increased, the change in air temperature generally decreased as seen by examining $\Delta \mathrm{T} 0$,e. An exception to this was Test \#668. However, this variation is small when compared with Test \#667 and is likely within the uncertainty of experimental data.

- The calculated Twb using the measured temperature and humidity at the test section generally matched the dry, cloud off values to within a few degrees with the majority agreeing to less than a degree.

- Similar to the $\mathrm{TWC}_{\text {bulk }}$ sweeps, RH Sweep 1 and 3 showed an abrupt change in change in melt ratio, $\eta_{\mathrm{e}}$. For RH Sweep 1, the transition occurred between $\mathrm{RH}_{0, \mathrm{i}} 15 \%$ and $35 \%$ while the transition occurred 
between $\mathrm{RH}_{0, \mathrm{i}}$ of 25 and $50 \%$ for sweep 3. $\mathrm{RH}$ sweep 2 showed a more linear behavior between $\eta_{\mathrm{e}}$ and $\mathrm{RH}_{0, \mathrm{i}} \cdot$

\section{Spray Bar Temperature Sweeps}

In these set of tests, the spray bar water and air temperatures were varied to see their effect on melt ratio at the test section. The facility target conditions and select measurements for the Spray Bar Temperature (SBT) sweeps are shown in Table 4. The spray bar temperatures tested were 45,110 , and $180^{\circ} \mathrm{F}$, which spans the facility limits. In general, the cases were chosen such that the $45^{\circ} \mathrm{F}$ produced a glaciated cloud. SBT Sweeps 1 and 2 compare MVDi (although there is a slight variation in TWC) while SBT Sweeps 3 and 4 compare the effect of TWC. Sweeps 1 and 2 were at the same Twb while sweeps 3 and 4 were at a colder Twb.

Figure 7 shows images from the SBT sweeps. The ice accretion for Test \#690 was not shown since the probe was not deiced from the prior test. The ice accretion in all of these tests shared some similar characteristics. Namely, the shapes were generally conformal to the shape of probe and there was little evidence of erosion. For these cases, the opacity of the ice is more generally clearer but has regions which have more of a rime appearance. Although the spray times varied for these tests between 4 and 5 minutes (see appendix), the ice thicknesses followed expected trends with the larger TWC values producing larger accretions.

Examination of Table 4 showed the following general trends:

- As spray bar temperature increased, the melt ratio increased in all cases from an almost completely glaciated cloud to a mostly liquid cloud. The liquid cloud is believed to be supercooled since it produced ice accretions.

- For the 15 micron tests (SBT Sweep 1, 3, and 4), the measured TWCm was always smaller the TWC $_{\text {bulk. }}$ For the larger $\mathrm{MVD}_{\mathrm{i}}$ of 40 microns, the trend again reversed with $\mathrm{TWCm}$ being greater than $\mathrm{TWC}_{\text {bulk. }}$.

- The change in humidity at the test section, $\Delta \omega_{\mathrm{e}}$, increased slightly with increasing water temperature. The largest variation occurred for SBT Sweep 4 which had the largest $\mathrm{TWC}_{\text {bulk. }}$.

- Similar to all of the previous data shown, the calculated Twb using the measured temperature and humidity at the test section generally matched the dry, cloud off values with the worst agreement occuring for SBT Sweep 4.

\section{Discussion}

A goal of the present research is to generate a prescribed mixed-phase condition at the test section of PSL similar to what occurs in an engine during ice crystal icing. In an engine, the mixed-phase environment is created by shattered ice particles that are partially melted in a warmer-than-freezing environment. For the present tests at PSL, the mixedphase cloud in an otherwise warmer-than-freezing environment is generated by partially freezing an initially liquid cloud using evaporative cooling. Regardless of whether or not the partial freezeout method sufficiently mimics engine icing, the dataset gathered in these experiments will help develop and validate ice-crystal (i.e. mixed-phase) icing models as well as further develop technology to measure the mixed-phase conditions.

The wet-bulb temperature can gauge whether the particles will supercool and / or freeze. Modelling results ${ }^{16}$ indicate that the water droplets ultimately achieve the static wet-bulb temperature with smaller droplet reaching that temperature more quickly than larger droplets. The static temperature (hence the static wet-bulb temperature) decreases along the length of PSL from the spray bars to the test section due to the flow acceleration. In the present experiments, the static temperature drop alone was often above freezing and evaporative cooling was required to freeze water droplets. The actual amount of freezing achieved (i.e. melt ratio) for a given tests is a complex function of the particle size distribution, flow speeds, air temperature, water temperature, pressure, and humidity. Analytical models ${ }^{22}$ are currently being developed to predict the melt ratio (and other PSL parameters) with data presented in this paper used to help develop and validate such models. However, the best method to determine the melt ratio is direct measurement although such measurements are not trivial.

The melt ratios presented in this paper were calculated using raw LWC and TWC measurements from the SEA multi-wire probe. The probe has both cylindrical and half-pipe shape elements (i.e. hot wires) which have different sensitivities to ice and water. These measurements are a valuable guide in gauging the relative fraction of water and ice but have not yet been validated to be the true values of LWC and TWC and some correction is anticipated. A hot wire requires complete evaporation of the impinging liquid and ice in order for the measurement to be completely 
accurate. However, it is expected that splash-loss increasingly occurs with larger liquid water droplets thus reducing the measured LWC. Also, ice particles may shatter and rebound from the half pipe element thereby reducing the response. Furthermore, the presence of ice crystals contribute a signal on the cylindrical LWC elements which is termed a "false response". All of these effects may vary with different flow conditions. In mixed-phase conditions, these effects are also present but the elements may respond differently. For example, the presence of a liquid film may help retain impacting ice crystal in the half pipe thereby allowing more water to evaporate and hence increasing the measured signal. To date, measurements from the probe are generally reported as raw measurements (as in this paper) or a constant correction factors is applied. There is not yet a generally accepted method to interpret the mixedphase measurements accounting for all of the factors mentioned above.

Another challenge in this experiment is the non-uniformity of the cloud. The multi-wire probe measurements were made at the centerline of the tunnel while the cloud-on humidity and temperature (which are critical to the calculation of wet-bulb temperature) were measured approximately 9" from the centerline. The radial variations of temperature and humidity, particularly with the cloud on, as well as cloud parameters such as water content and PSD are not yet understood at PSL making interpretation of results more difficult. Furthermore, the present dataset is incomplete as particle size measurements at the test section are needed to better interpret results.

Much of the data presented in the results section showed expected trends while some provided further insight. For example, increasing the plenum humidity reduced the evaporation of the cloud as expected. In addition, the temperature of the air decreased with increasing evaporation - it is now better understood from recent modelling efforts ${ }^{16}$ how the cloud and air are coupled from an aero-thermal perspective. When using the new cloud-on temperature and humidity, the resulting wet-bulb temperatures were generally within a degree or two of the cloud-off values. This may suggest that the wet-bulb temperature is somehow representative of the total energy of system. In other words, the energy of evaporation comes solely from the sensible energy change of the air and this temperature and humidity change occurs in such a way where the wet-bulb temperature remains approximately constant under an otherwise adiabatic process. Further testing and analysis are required to verify this interpretation.

Other observations in the dataset were harder to interpret. For example, the variation of melt ratio with TWC produced non-monotonic trends. Simply increasing the bulk total water content from 0.5 to $1 \mathrm{~g} / \mathrm{m}^{3}$, with other conditions roughly constant, caused the cloud to become glaciated. The cloud remained glaciated for higher TWC until about reaching $5 \mathrm{~g} / \mathrm{m}^{3}$ where some liquid was again measured although the particle size for the $5 \mathrm{~g} / \mathrm{m}^{3}$ tests was somewhat larger. Some of the interpretation difficulties are due to measurement uncertainties, cloud uniformity variations, or lack of additional data such as measured PSD. Ongoing modelling efforts and future tests will help interpret these results.

The response of the multi-wire probe to different $M V D_{i}$ requires further interpretation. The measured $T W C m$ was generally much lower when compared with $\mathrm{TWC}_{\text {bulk }}$ for the $\mathrm{MVD}_{\mathrm{i}} \sim 15 \mu$. For the larger $\mathrm{MVD}_{\mathrm{i}} \sim 40 \mu$, the TWCm was generally larger than TWCbulk (sometimes by a factor of 2 or more). A possible explanation for this behavior could be that the larger particles are being forced towards the center of the tunnel resulting in locally higher water contents. Other contributing factors are that the smaller $\mathrm{MVD}_{\mathrm{i}}$ clouds may more readily evaporate compared with larger $\mathrm{MVD}_{\mathrm{i}}$ clouds.

Finally, many of the ice accretions observed in the presented tests had a glazy appearance which conformed to the leading edge of the surface. The higher melt ratios and presence of ice accretions suggest supercooled water. As the water droplets freeze, they likely transition through a supercooled state. By the time they reach the test section at PSL, the smallest droplets would have frozen first with the larger droplets taking longer. Thus, the clouds generated during the present tests likely contain a mixture of smaller ice particles with large droplets of supercooled water. This is different than what occurs in an engine where the smallest particles melt first with larger particles remaining frozen. Further work is required to verify the state and temperature of the droplets at the PSL test section. In addition, the ice accretions generated with partially frozen clouds need to be compared to ice accretions generated with partially melted clouds.

\section{Conclusion}

NASA is studying the fundamental physical mechanisms of icing that occurs in core compressor regions of jet engines when ingesting ice crystals. Building on research dating back to 2009, NASA seeks to expand engine aerothermodynamic modeling capability to predictively assess the onset of icing in current and future aircraft during flight operation. Key enablers for this modelling capability are fundamental experiments to understand ice-crystal icing physics that determine the conditions favorable for ice accretion and the rate of ice growth. 
An objective of NASA's fundamental ice crystal icing research is to develop the capability to generate a prescribed mixed-phase condition similar to what occurs inside a jet engine when accreting ice. However, it is desired to generate that environment outside of an engine to facilitate study. NASA is examining PSL as a potential test-bed for such research. Data was presented from preliminary testing at PSL performed during May 2015 where different mixedphase clouds were generated by varying various facility parameters. The primary parameters varied include total water content, plenum humidity, and spray bar air and water temperature. Within these primary parameters, particle size and wet-bulb temperature was further varied. An abundance of data was presented in the previous section. Clouds ranging from fully-liquid (non-supercooled), fully-liquid (supercooled as evidenced from ice accretions), mixed-phase including both high and low melt ratio, and fully glaciated were believed to have been observed.

Much of the data presented showed expected trends while some provided further insight and still others were difficult to interpret. For example, the data suggests that the humidity and temperature at the test section changes in such a way that the wet-bulb temperature remains nearly constant. An example of a difficult-to-interpret result was the non-monotonic variation of melt ratio with TWC. Some of these difficulties are due to measurement uncertainties, cloud uniformity variations, or lack of additional data such as measured particle size distribution. Modelling efforts and additional experiments such as those just completed in March 2016 will help interpret these results. 


\section{Figures}

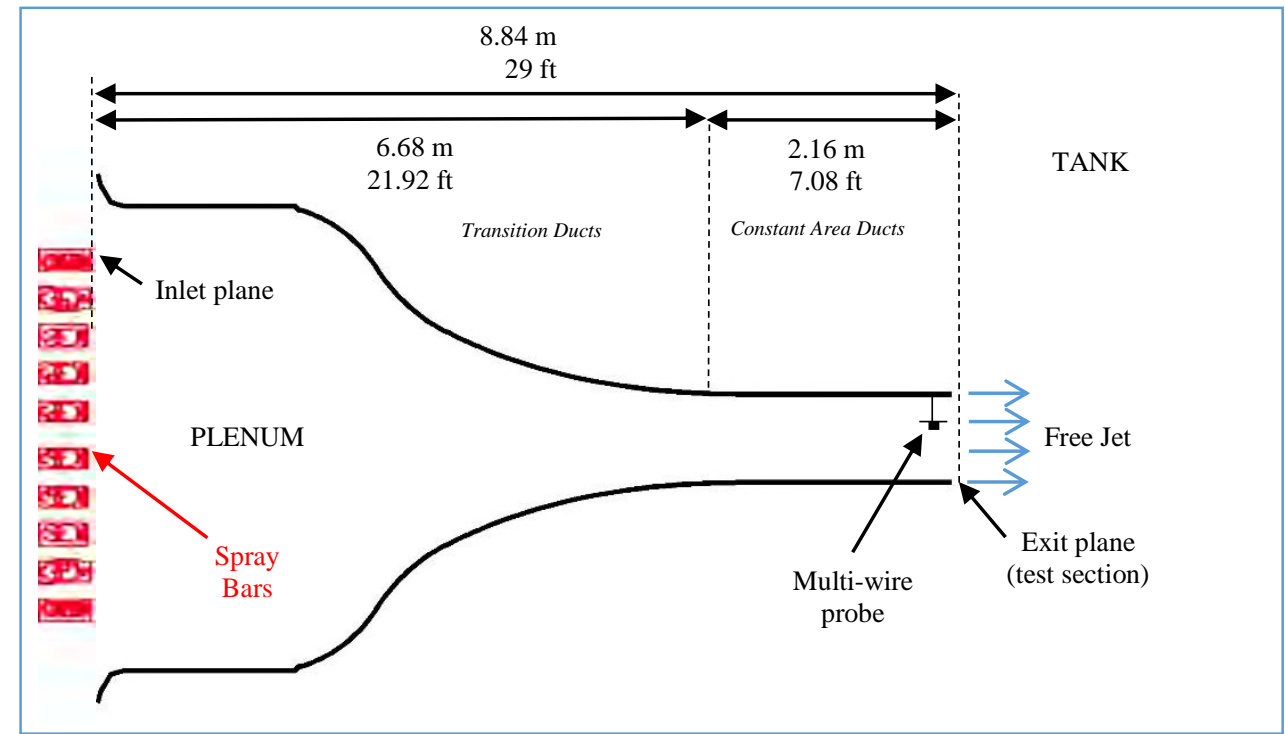

Figure 1. Schematic of experiment.

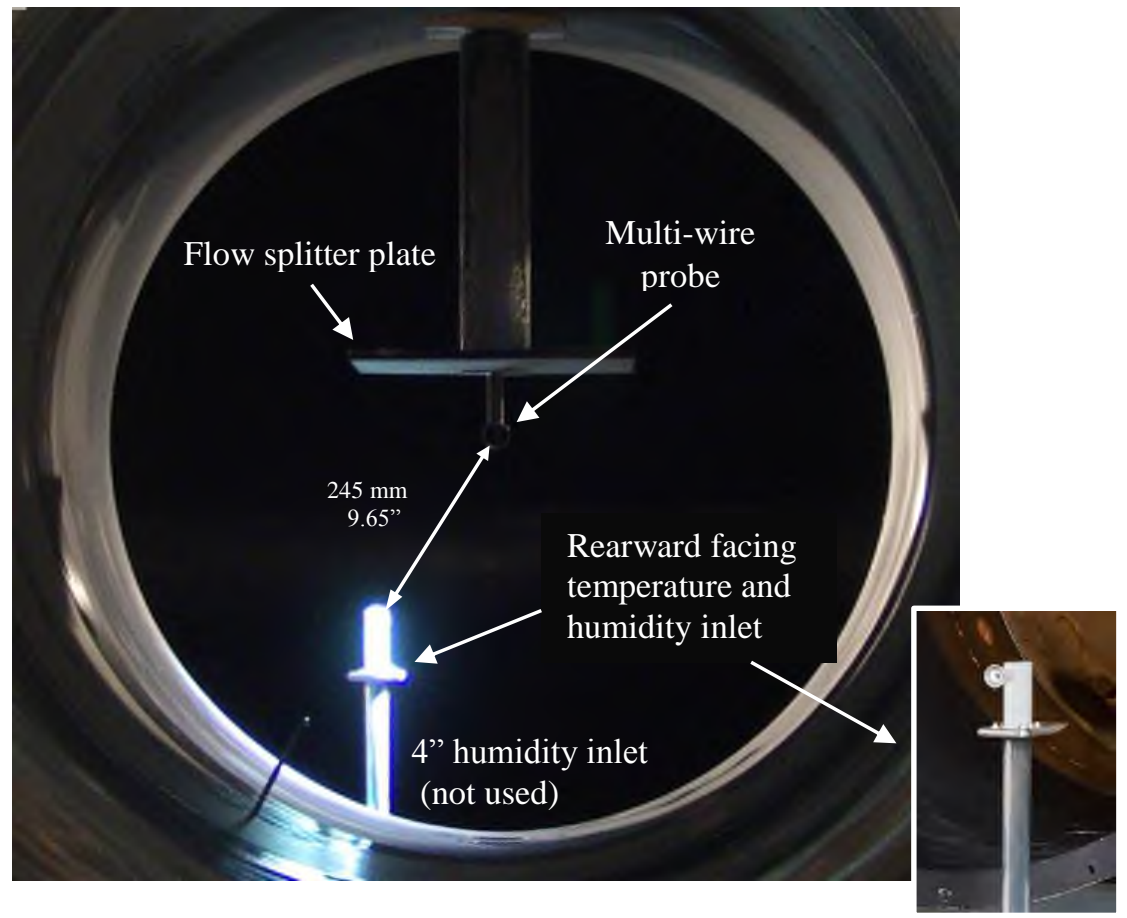

Figure 2. Hardware configuration used in preliminary testing on May 28, 2015. The larger image was taken using a camera embedded in the spray bar system (forward looking aft). The inset image shows the rearward facing temperature and humidity inlet from a perspective at back of the tunnel looking forward. 


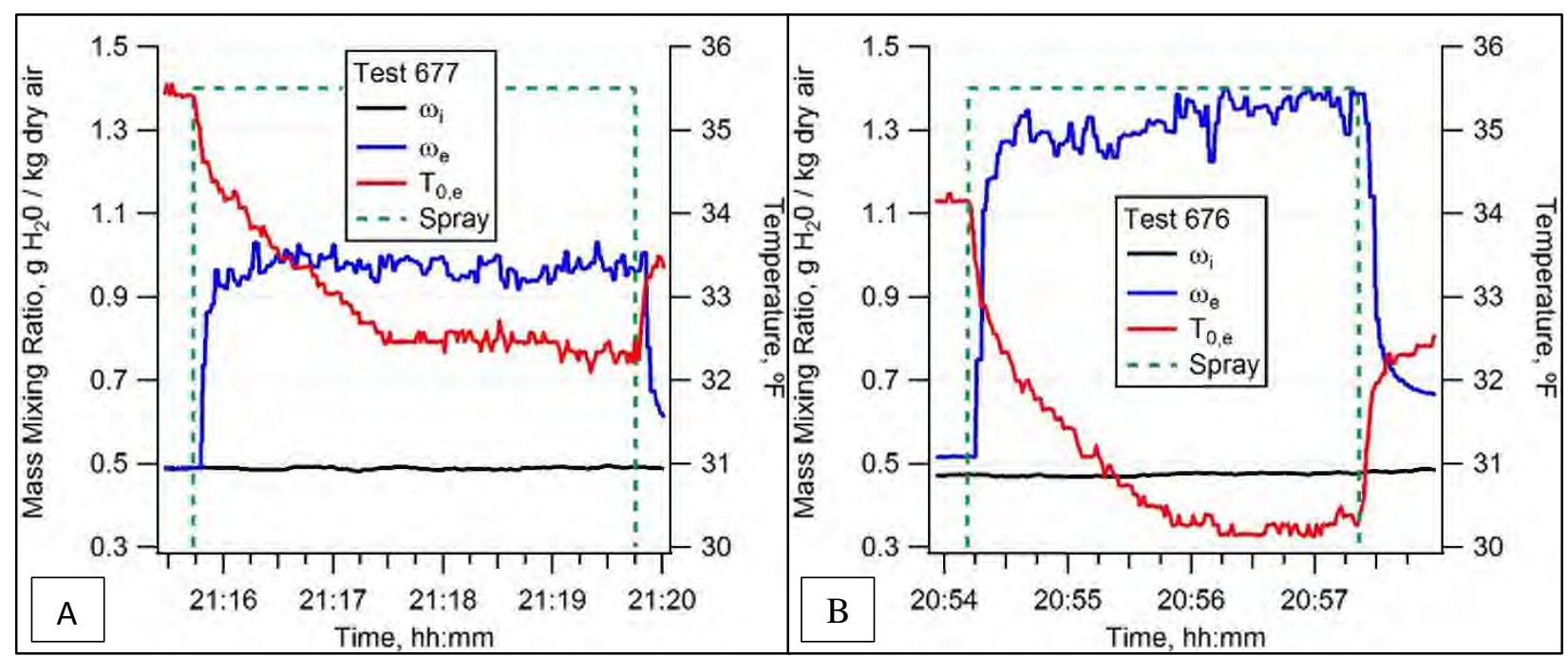

Figure 3. Sample humidity and temperature data taken during Test \#677 (A) and Test \#676 (B). In each graph, two humidity measurements are shown: plenum $\left(\omega_{i}\right)$ and test section $\left(\omega_{e}\right)$. The measurements at the test section use the rearward facing temperature and humidity inlet. The temperature measurements at the test section $\left(T_{0, e}\right)$ have been corrected to total temperature. 
Table 1. Facility target conditions and select measurements during two TWC sweeps. Actual conditions are in the appendix.

\begin{tabular}{|c|c|c|c|c|c|c|c|c|c|}
\hline Test Series -> & \multicolumn{5}{|c|}{ TWC Sweep 1} & \multicolumn{4}{|c|}{ TWC Sweep 2} \\
\hline \multicolumn{10}{|c|}{ Facility Target Conditions } \\
\hline $\mathrm{P}_{0, \mathrm{i}}(\mathrm{psia})$ & \multicolumn{5}{|c|}{12.7} & \multicolumn{4}{|c|}{6.5} \\
\hline $\mathrm{P}_{\mathrm{s}, \mathrm{e}}(\mathrm{psia})$ & \multicolumn{5}{|c|}{12.1} & \multicolumn{4}{|c|}{6.2} \\
\hline $\mathrm{V}_{\mathrm{e}}(\mathrm{m} / \mathrm{s})$ & \multicolumn{5}{|c|}{85} & \multicolumn{4}{|c|}{85} \\
\hline Altitude (kft) & \multicolumn{5}{|c|}{5.3} & \multicolumn{4}{|c|}{22.2} \\
\hline $\mathrm{T}_{0, \mathrm{i}}\left({ }^{\circ} \mathrm{F}\right)$ & \multirow{2}{*}{\multicolumn{5}{|c|}{$\begin{array}{l}43.9 \\
37.4\end{array}$}} & \\
\hline $\mathrm{T}_{\mathrm{s}, \mathrm{e}, \text { off }}\left({ }^{\circ} \mathrm{F}\right)$ & & & & & & \multicolumn{4}{|c|}{36.5} \\
\hline $\mathrm{RH}_{0, \mathrm{i}}(-)$ & \multicolumn{5}{|c|}{$\begin{array}{c}37.4 \\
0.1\end{array}$} & \multicolumn{4}{|c|}{0.1} \\
\hline$\omega_{\mathrm{i}}(\mathrm{g} / \mathrm{kg})$ & \multicolumn{5}{|c|}{.70} & \multicolumn{4}{|c|}{1.3} \\
\hline $\mathrm{Twb}_{0, \mathrm{e}, \text { off }}\left({ }^{\circ} \mathrm{F}\right)$ & \multicolumn{5}{|c|}{28} & \multirow{2}{*}{\multicolumn{4}{|c|}{$\begin{array}{l}22 \\
19\end{array}$}} \\
\hline $\mathrm{Twb}_{\mathrm{s}, \mathrm{e}, \mathrm{off}}\left({ }^{\circ} \mathrm{F}\right)$ & \multicolumn{5}{|c|}{24} & & & & \\
\hline $\mathrm{TWC}_{\text {bulk }}\left(\mathrm{g} / \mathrm{m}^{3}\right)$ & .55 & 1.0 & 2.2 & 3.5 & 4.9 & .60 & 1.0 & 2.3 & 4.9 \\
\hline $\mathrm{MVD}_{\mathrm{i}}(\mu \mathrm{m})$ & \multicolumn{4}{|c|}{15} & 19 & \multicolumn{3}{|c|}{15} & 19 \\
\hline \multicolumn{10}{|c|}{ Measurements } \\
\hline Test \# & 666 & 667 & 665 & 664 & 663 & 678 & 679 & 680 & 681 \\
\hline $\mathrm{TWC}_{\mathrm{m}}\left(\mathrm{g} / \mathrm{m}^{3}\right)$ & .28 & .29 & 1.9 & 3.0 & 6.4 & .10 & .22 & 1.9 & 4.3 \\
\hline$\eta_{\mathrm{e}}(\%)$ & 79 & 16 & 10 & 10 & 20 & 27 & 19 & 8 & 8 \\
\hline$\Delta \omega_{\mathrm{e}}(\mathrm{g} / \mathrm{kg})$ & .71 & 1.3 & 2.1 & 2.1 & 2.3 & 1.4 & 1.7 & 2.8 & 3.7 \\
\hline$\Delta \mathrm{T}_{0, \mathrm{e}}\left({ }^{\circ} \mathrm{F}\right)$ & -3.3 & -5.4 & -9.2 & -8.7 & -8.4 & -5.7 & -7.8 & -12 & -14 \\
\hline $\mathrm{Twb}_{0, \mathrm{e}, \mathrm{on}}\left({ }^{\circ} \mathrm{F}\right)$ & 28 & 28 & 28 & 28 & 28 & 22 & 22 & 22 & 22 \\
\hline $\mathrm{Twb}_{\mathrm{s}, \mathrm{e}, \mathrm{on}}\left({ }^{\circ} \mathrm{F}\right)$ & 24 & 25 & 24 & 24 & 25 & 19 & 19 & 19 & 19 \\
\hline Ice Accr. (Y/N) & $\mathrm{Y}$ & $\mathrm{N}$ & $\mathrm{N}$ & $\mathrm{N}$ & $\mathrm{Y}$ & $\mathrm{N}$ & $\mathrm{N}$ & $\mathrm{N}$ & $\mathrm{N}$ \\
\hline
\end{tabular}

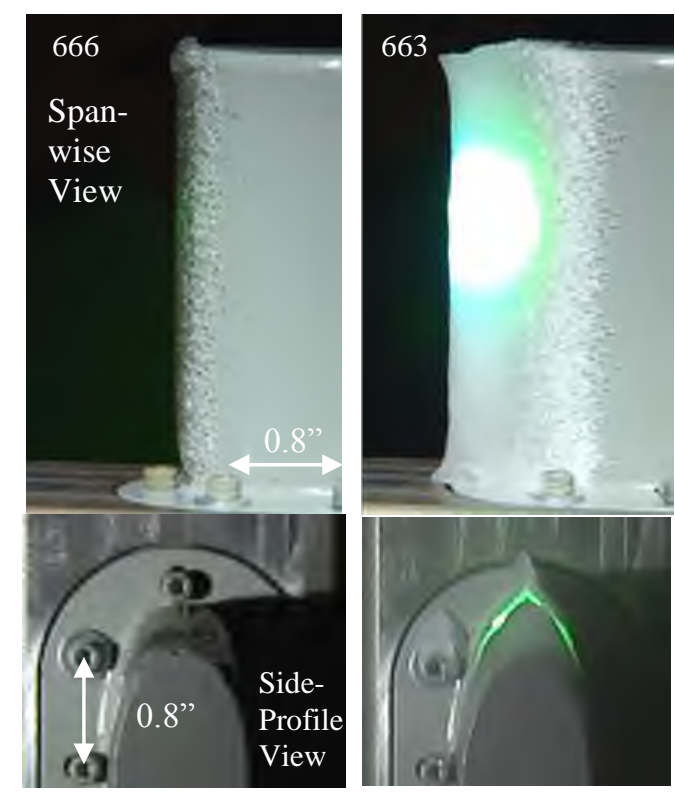

Figure 4. Images extracted from video showing various ice accretion shapes seen on the humidity / temperature probe inlet at the end of the given spray. The green light seen in some of the images is the laser from the Phase Doppler Interferometer and fortuitously helped to outline the ice shape as seen in the rightmost. 
Table 2. Facility target conditions and select measurements during two TWC sweeps. Actual conditions are in the appendix.

\begin{tabular}{|c|c|c|c|c|c|c|c|c|}
\hline Test Series -> & \multicolumn{4}{|c|}{ TWC Sweep 3} & \multicolumn{4}{|c|}{ TWC Sweep 4} \\
\hline \multicolumn{9}{|c|}{ Facility Target Conditions } \\
\hline $\mathrm{P}_{0, \mathrm{i}}(\mathrm{psia})$ & \multicolumn{4}{|c|}{12.7} & \multicolumn{4}{|c|}{12.7} \\
\hline $\mathrm{P}_{\mathrm{s}, \mathrm{e}}(\mathrm{psia})$ & \multicolumn{4}{|c|}{12.1} & \multicolumn{4}{|c|}{12.1} \\
\hline $\mathrm{V}_{\mathrm{e}}(\mathrm{m} / \mathrm{s})$ & \multicolumn{4}{|c|}{85} & \multicolumn{4}{|c|}{85} \\
\hline Altitude (kft) & \multicolumn{4}{|c|}{5.3} & \multicolumn{4}{|c|}{5.3} \\
\hline $\mathrm{T}_{0, \mathrm{i}}\left({ }^{\circ} \mathrm{F}\right)$ & \multirow{2}{*}{\multicolumn{4}{|c|}{$\begin{array}{l}39.6 \\
33.1\end{array}$}} & \multirow{2}{*}{\multicolumn{4}{|c|}{$\begin{array}{l}35.2 \\
28.8\end{array}$}} \\
\hline $\mathrm{T}_{\mathrm{s}, \mathrm{e}, \mathrm{off}}\left({ }^{\circ} \mathrm{F}\right)$ & & & & & & & & \\
\hline $\mathrm{RH}_{0, \mathrm{i}}(-)$ & \multicolumn{4}{|c|}{0.1} & \multicolumn{4}{|c|}{0.1} \\
\hline$\omega_{\mathrm{i}}(\mathrm{g} / \mathrm{kg})$ & \multicolumn{4}{|c|}{0.60} & \multicolumn{4}{|c|}{0.50} \\
\hline $\mathrm{Twb}_{0, \mathrm{e}, \mathrm{off}}\left({ }^{\circ} \mathrm{F}\right)$ & \multicolumn{4}{|c|}{26} & \multicolumn{4}{|c|}{23} \\
\hline $\mathrm{Twb}_{\mathrm{s}, \mathrm{e}, \mathrm{off}}\left({ }^{\circ} \mathrm{F}\right)$ & \multicolumn{4}{|c|}{22} & \multicolumn{4}{|c|}{19} \\
\hline $\mathrm{TWC}_{\text {bulk }}\left(\mathrm{g} / \mathrm{m}^{3}\right)$ & .80 & 1.4 & 2.3 & 5.0 & .80 & 1.4 & 2.3 & 5.1 \\
\hline $\operatorname{MVD}_{\mathrm{i}}(\mu \mathrm{m})$ & \multicolumn{4}{|c|}{40} & \multicolumn{4}{|c|}{40} \\
\hline \multicolumn{9}{|c|}{ Measurements } \\
\hline Test \# & 670 & 671 & 672 & 673 & 677 & 676 & 675 & 674 \\
\hline $\mathrm{TWC}_{\mathrm{m}}\left(\mathrm{g} / \mathrm{m}^{3}\right)$ & 1.4 & 2.9 & 4.3 & 10 & 1.5 & 3.3 & 3.6 & 9.6 \\
\hline$\eta_{\mathrm{e}}(\%)$ & 69 & 66 & 23 & 27 & 70 & 67 & 19 & 20 \\
\hline$\Delta \omega_{\mathrm{e}}(\mathrm{g} / \mathrm{kg})$ & .55 & .87 & 1.3 & 2.3 & .49 & .85 & 1.3 & 2.1 \\
\hline$\Delta \mathrm{T}_{0, \mathrm{e}}\left({ }^{\circ} \mathrm{F}\right)$ & -3.0 & -4.1 & -5.2 & -6.7 & -3.1 & -3.9 & -3.2 & -6.9 \\
\hline $\operatorname{Twb}_{0, \mathrm{e}, \mathrm{on}}\left({ }^{\circ} \mathrm{F}\right)$ & 26 & 26 & 26 & 25 & 23 & 23 & 22 & 23 \\
\hline $\mathrm{Twb}_{\mathrm{s}, \mathrm{e}, \mathrm{on}}\left({ }^{\circ} \mathrm{F}\right)$ & 22 & 22 & 23 & 25 & 19 & 19 & 19 & 19 \\
\hline Ice Accr. (Y/N) & $\mathrm{Y}$ & $\mathrm{Y}$ & $\mathrm{Y}$ & $\mathrm{Y}$ & $\mathrm{Y}$ & $\mathrm{Y}$ & $\mathrm{Y}$ & $\mathrm{Y}$ \\
\hline
\end{tabular}
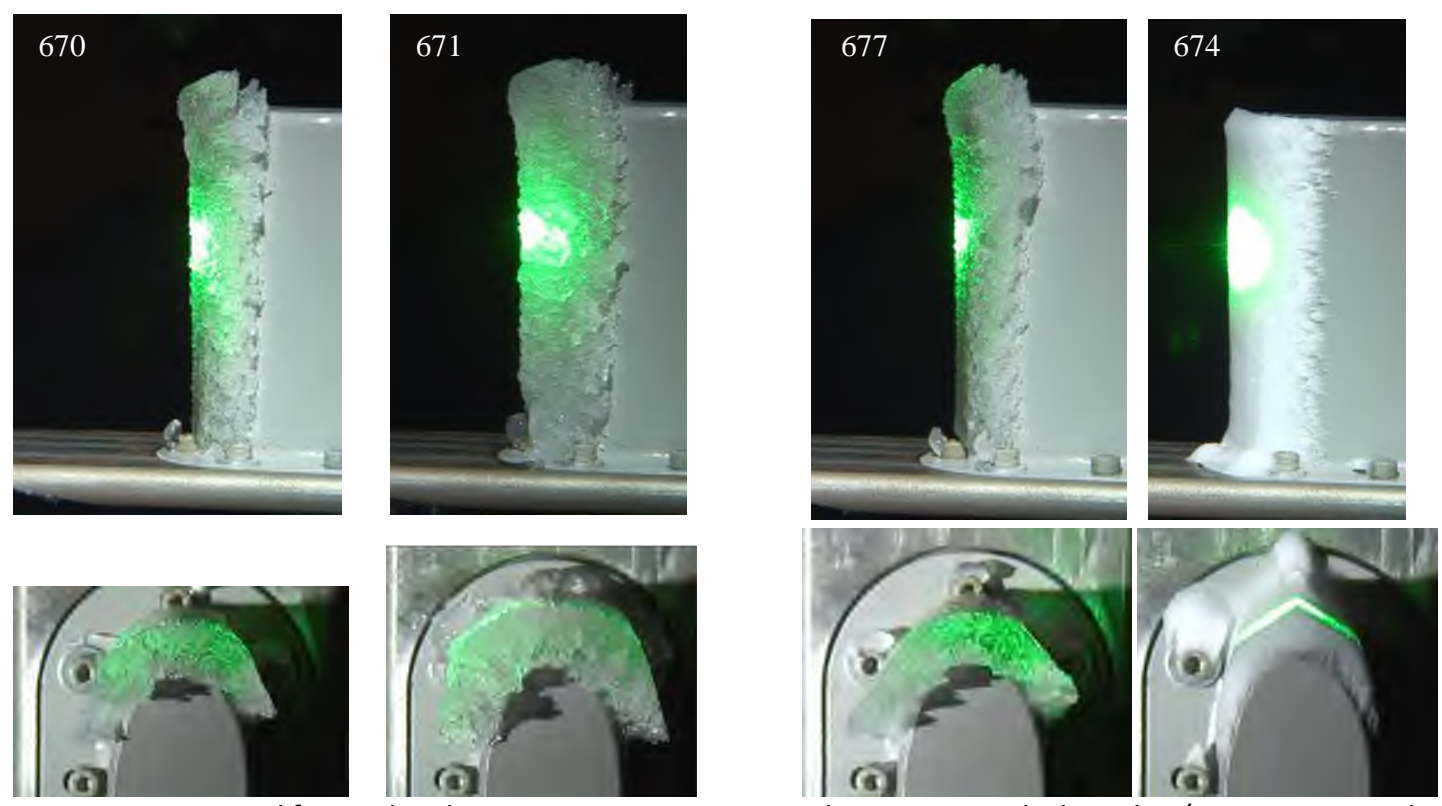

Figure 5. Images extracted from video showing various ice accretion shapes seen on the humidity / temperature probe inlet at the end of the given spray. See additional comments and scale in Figure 4. 
Table 3. Facility target conditions and select measurements during three RH sweeps. Actual conditions are in the appendix.

\begin{tabular}{|c|c|c|c|c|c|c|c|c|c|}
\hline Test Series -> & \multicolumn{3}{|c|}{ RH Sweep 1} & \multicolumn{3}{|c|}{ RH Sweep 2} & \multicolumn{3}{|c|}{ RH Sweep 3} \\
\hline \multicolumn{10}{|c|}{ Facility Target Conditions } \\
\hline $\mathrm{P}_{0, \mathrm{i}}$ (psia) & \multicolumn{3}{|c|}{12.7} & \multicolumn{3}{|c|}{6.5} & \multicolumn{3}{|c|}{6.5} \\
\hline $\mathrm{P}_{\mathrm{s}, \mathrm{e}}(\mathrm{psia})$ & \multicolumn{3}{|c|}{12.1} & \multicolumn{3}{|c|}{5.8} & \multicolumn{3}{|c|}{6.2} \\
\hline $\mathrm{V}_{\mathrm{e}}(\mathrm{m} / \mathrm{s})$ & \multicolumn{3}{|c|}{85} & \multicolumn{3}{|c|}{135} & \multicolumn{3}{|c|}{85} \\
\hline Altitude $(\mathrm{kft})$ & \multicolumn{3}{|c|}{5.3} & \multicolumn{3}{|c|}{23.7} & \multicolumn{3}{|c|}{22.2} \\
\hline $\begin{array}{c}\mathrm{T}_{0, \mathrm{i}}\left({ }^{\circ} \mathrm{F}\right) \\
\mathrm{T}_{\mathrm{s}, \mathrm{e}, \text { off }}\left({ }^{\circ} \mathrm{F}\right)\end{array}$ & \multicolumn{3}{|c|}{$\begin{array}{l}43.9 \\
37.4 \\
\end{array}$} & \multicolumn{3}{|c|}{$\begin{array}{l}47.2 \\
31.0 \\
\end{array}$} & \multicolumn{3}{|c|}{$\begin{array}{l}42.9 \\
36.5\end{array}$} \\
\hline $\mathrm{RH}_{0, \mathrm{i}}(-)$ & .10 & .35 & .50 & .10 & .30 & .50 & .10 & .25 & .50 \\
\hline$\omega_{\mathrm{i}}(\mathrm{g} / \mathrm{kg})$ & .70 & 2.4 & 3.5 & 1.5 & 4.7 & 7.8 & 1.3 & 3.3 & 6.6 \\
\hline Twb $_{0, \mathrm{e}, \mathrm{off}}\left({ }^{\circ} \mathrm{F}\right)$ & 28 & 33 & 35 & 25 & 30 & 35 & 22 & 26 & 32 \\
\hline Twb $_{\mathrm{s}, \mathrm{e}, \mathrm{off}}\left({ }^{\circ} \mathrm{F}\right)$ & 24 & 29 & 31 & 16 & 22 & 28 & 19 & 23 & 29 \\
\hline $\mathrm{TWC}_{\text {bulk }}\left(\mathrm{g} / \mathrm{m}^{3}\right)$ & \multicolumn{3}{|c|}{1.0} & \multicolumn{3}{|c|}{3.1} & \multicolumn{3}{|c|}{4.9} \\
\hline $\operatorname{MVD}_{\mathrm{i}}(\mu \mathrm{m})$ & \multicolumn{3}{|c|}{15} & \multicolumn{3}{|c|}{19} & \multicolumn{3}{|c|}{19} \\
\hline \multicolumn{10}{|c|}{ Measurements } \\
\hline Test \# & 667 & 668 & 669 & 684 & 685 & 686 & 681 & 682 & 683 \\
\hline $\mathrm{TWC}_{\mathrm{m}}\left(\mathrm{g} / \mathrm{m}^{3}\right)$ & .29 & .88 & 1.1 & 3.7 & 4.5 & 4.9 & 4.3 & 4.9 & 5.3 \\
\hline$\eta_{\mathrm{e}}(\%)$ & 16 & 81 & 82 & 15 & 45 & 70 & 8 & 11 & 74 \\
\hline$\Delta \omega_{\mathrm{e}}(\mathrm{g} / \mathrm{kg})$ & 1.3 & .99 & .83 & 3.2 & 2.4 & 1.7 & 3.6 & 3.1 & 1.9 \\
\hline$\Delta \mathrm{T}_{0, \mathrm{e}}\left({ }^{\circ} \mathrm{F}\right)$ & -5.4 & -5.7 & -4.3 & -12 & -10 & -6.8 & -14 & -11 & -7.5 \\
\hline $\mathrm{Twb}_{0, \mathrm{e}, \mathrm{on}}\left({ }^{\circ} \mathrm{F}\right)$ & 28 & 33 & 35 & 23 & 29 & 32 & 22 & 26 & 32 \\
\hline $\mathrm{Twb}_{\mathrm{s}, \mathrm{e}, \mathrm{on}}\left({ }^{\circ} \mathrm{F}\right)$ & 25 & 29 & 31 & 16 & 23 & 28 & 19 & 23 & 29 \\
\hline Ice Accr. (Y/N) & $\mathrm{N}$ & $\mathrm{N}$ & $\mathrm{N}$ & $\mathrm{N}$ & $\mathrm{Y}$ & $\mathrm{N}$ & $\mathrm{N}^{*}$ & $\mathrm{Y}$ & $\mathrm{N}$ \\
\hline
\end{tabular}

* Trace ice on base of probe

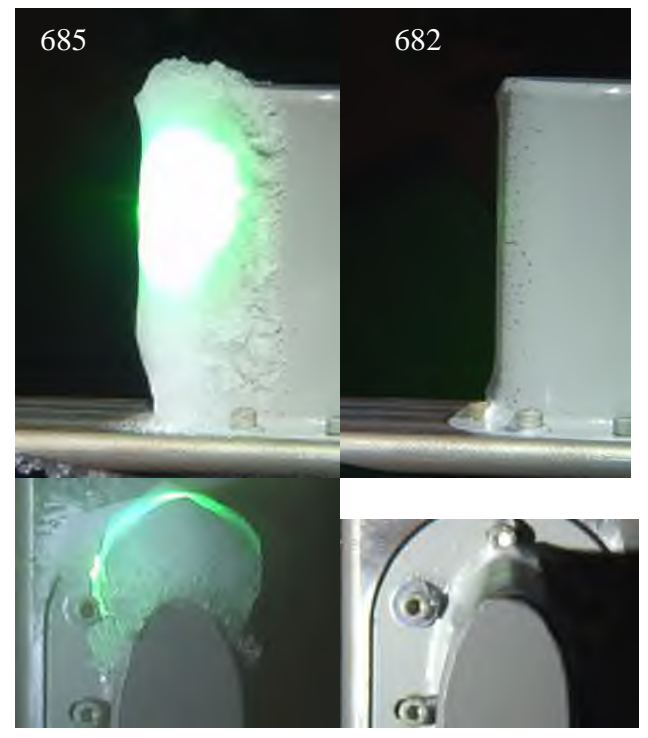

Figure 6. Images extracted from video showing various ice accretion shapes seen on the humidity / temperature probe inlet at the end of the given spray. See additional comments and scale in Figure 4. 
Table 4. Facility target conditions \& select measurements during spray bar temp. sweeps. Actual conditions are in the appendix.

\begin{tabular}{|c|c|c|c|c|c|c|c|c|c|c|c|c|}
\hline Test Series -> & & & & & & & & & & & & \\
\hline \multicolumn{13}{|c|}{ Facility Target Conditions } \\
\hline $\mathrm{P}_{0, \mathrm{i}}(\mathrm{psia})$ & \multicolumn{6}{|c|}{12.7} & \multicolumn{6}{|c|}{6.5} \\
\hline $\mathrm{P}_{\mathrm{s}, \mathrm{e}}(\mathrm{psia})$ & \multicolumn{6}{|c|}{12.1} & \multicolumn{6}{|c|}{6.2} \\
\hline $\mathrm{V}_{\mathrm{e}}(\mathrm{m} / \mathrm{s})$ & \multicolumn{6}{|c|}{85} & \multicolumn{6}{|c|}{85} \\
\hline Altitude (kft) & \multicolumn{6}{|c|}{5.3} & \multicolumn{6}{|c|}{22.2} \\
\hline $\mathrm{T}_{0, \mathrm{i}}\left({ }^{\circ} \mathrm{F}\right)$ & \multirow{2}{*}{\multicolumn{6}{|c|}{$\begin{array}{l}43.9 \\
37.4\end{array}$}} & \multirow{2}{*}{\multicolumn{6}{|c|}{$\begin{array}{l}42.9 \\
36.5\end{array}$}} \\
\hline $\mathrm{T}_{\mathrm{s}, \mathrm{e}, \mathrm{off}}\left({ }^{\circ} \mathrm{F}\right)$ & & & & & & & & & & & & \\
\hline $\mathrm{RH}_{0, \mathrm{i}}(-)$ & \multicolumn{6}{|c|}{.10} & \multicolumn{6}{|c|}{.10} \\
\hline$\omega_{\mathrm{i}}(\mathrm{g} / \mathrm{kg})$ & \multicolumn{6}{|c|}{.70} & \multicolumn{6}{|c|}{1.3} \\
\hline $\mathrm{Twb}_{0, \mathrm{e}, \mathrm{off}}\left({ }^{\circ} \mathrm{F}\right)$ & \multicolumn{6}{|c|}{28} & \multicolumn{6}{|c|}{22} \\
\hline $\mathrm{Twb}_{\mathrm{s}, \mathrm{e}, \text { off }}\left({ }^{\circ} \mathrm{F}\right)$ & \multicolumn{6}{|c|}{24} & \multicolumn{6}{|c|}{19} \\
\hline $\mathrm{T}_{\text {water,i }}\left({ }^{\circ} \mathrm{F}\right)$ & 45 & 110 & 180 & 45 & 110 & 180 & 45 & 110 & 180 & 45 & 110 & 180 \\
\hline $\mathrm{TWC}_{\text {bulk }}\left(\mathrm{g} / \mathrm{m}^{3}\right)$ & \multicolumn{3}{|c|}{1.0} & \multicolumn{3}{|c|}{0.8} & \multicolumn{3}{|c|}{1.0} & \multicolumn{3}{|c|}{2.3} \\
\hline $\operatorname{MVD}_{\mathrm{i}}(\mu \mathrm{m})$ & \multicolumn{3}{|c|}{15} & \multicolumn{3}{|c|}{40} & \multicolumn{6}{|c|}{15} \\
\hline \multicolumn{13}{|c|}{ Measurements } \\
\hline Test \# & 667 & 690 & 691 & \multirow{9}{*}{ N/A } & 689 & 692 & 679 & 688 & 693 & 680 & 687 & 694 \\
\hline $\mathrm{TWC}_{\mathrm{m}}\left(\mathrm{g} / \mathrm{m}^{3}\right)$ & .29 & .51 & .42 & & 1.3 & 1.2 & .22 & .29 & .25 & 1.9 & 1.7 & 1.4 \\
\hline$\eta_{\mathrm{e}}(\%)$ & 16 & 83 & 83 & & 70 & 68 & 19 & 73 & 86 & 8 & 60 & 87 \\
\hline$\Delta \omega_{\mathrm{e}}(\mathrm{g} / \mathrm{kg})$ & 1.3 & 1.3 & 1.4 & & .69 & .73 & 1.7 & 1.9 & 2.0 & 2.8 & 3.2 & 3.6 \\
\hline$\Delta \mathrm{T}_{0, \mathrm{e}}\left({ }^{\circ} \mathrm{F}\right)$ & -5.4 & -5.5 & -6.0 & & -3.3 & -3.3 & -7.8 & -7.4 & -8.9 & -12.4 & $\begin{array}{ll}-13.8 \\
\end{array}$ & -13 \\
\hline $\mathrm{Twb}_{0, \mathrm{e}, \mathrm{on}}\left({ }^{\circ} \mathrm{F}\right)$ & 28 & 28 & 28 & & 28 & 28 & 22 & 21 & 23 & 22 & 22 & 22 \\
\hline $\mathrm{Twb}_{\mathrm{s}, \mathrm{e}, \mathrm{on}}\left({ }^{\circ} \mathrm{F}\right)$ & 25 & 24 & 24 & & 24 & 24 & 19 & 18 & 18 & 19 & 18 & 19 \\
\hline & & & & & & & & & & & & \\
\hline Ice Accr. (Y/N) & $\mathrm{N}$ & $\mathrm{Y}^{*}$ & $\mathrm{Y}$ & & $\mathrm{Y}$ & $\mathrm{Y}$ & $\mathrm{N}$ & Trace* & $\mathrm{Y}$ & $\mathrm{N}$ & $\mathrm{Y}$ & $\mathrm{Y}$ \\
\hline
\end{tabular}

* No image available
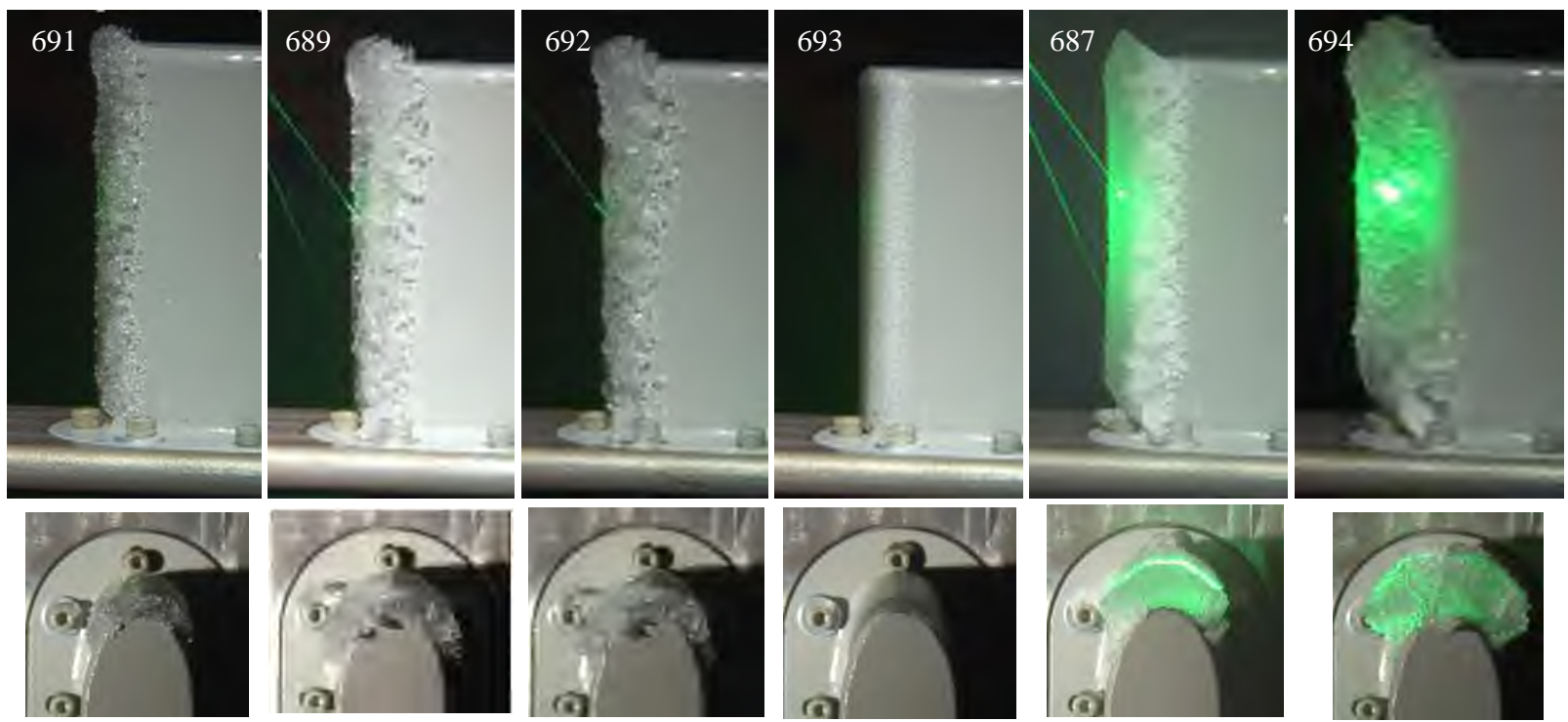

Figure 7. Images extracted from video showing various ice accretion shapes seen on the humidity / temperature probe inlet at the end of the given spray. See additional comments and scale in Figure 4. 


\section{Appendix}

The following data tables list the as-run facility conditions and measurements for the test points presented in this paper. In each table, column 3 denotes whether the parameter was measured ("meas."), calculated ("calc."), or a facility target ("target") value. 
Table 5. Actual run conditions during two TWC sweeps shown in Table 1.

\begin{tabular}{|c|c|c|c|c|c|c|c|c|c|c|c|}
\hline Symbol & UNIT & Source & & \multicolumn{8}{|c|}{ DATA } \\
\hline Test & $\#$ & $\log$ & 666 & 667 & 665 & 664 & 663 & 678 & 679 & 680 & 681 \\
\hline Ice Accretion & $(\mathrm{Y} / \mathrm{N})$ & Notes & $\mathrm{Y}$ & $\mathrm{N}$ & $\mathrm{N}+$ & $\mathrm{N}+$ & Y+ & $\mathrm{N}$ & $\mathrm{N}$ & $\mathrm{N}$ & Y- \\
\hline Altitude & $(\mathrm{kft})$ & $\log$ & 5.34 & 5.34 & 5.34 & 5.34 & 5.35 & 22.15 & 22.16 & 22.16 & 22.20 \\
\hline $\mathbf{P}_{0}$ & (psi) & $\log$ & 12.65 & 12.64 & 12.65 & 12.64 & 12.65 & 6.49 & 6.47 & 6.46 & 6.46 \\
\hline $\mathbf{P}_{\text {tank }}$ & (psi) & Log & 12.07 & 12.06 & 12.07 & 12.07 & 12.06 & 6.17 & 6.16 & 6.16 & 6.15 \\
\hline $\mathrm{P}_{\mathrm{s}, \mathrm{e}}$ & (psi) & Escort & 12.14 & 12.14 & 12.14 & 12.14 & 12.14 & 6.2 & 6.2 & 6.2 & 6.2 \\
\hline $\mathrm{M}_{\mathrm{e}}$ & $(-)$ & Escort & 0.25 & 0.25 & 0.25 & 0.25 & 0.25 & 0.26 & 0.26 & 0.26 & 0.26 \\
\hline$v_{e}$ & $(\mathrm{~m} / \mathrm{s})$ & Escort & 85.0 & 85.0 & 85.0 & 85.0 & 85.0 & 84.9 & 84.5 & 84.5 & 84.5 \\
\hline $\mathbf{T}_{\mathbf{0}}$ & $\left({ }^{\circ} \mathbf{F}\right)$ & Escort & 43.6 & 44.0 & 43.7 & 43.6 & 44.0 & 42.5 & 43.3 & 43.4 & 43.3 \\
\hline $\mathrm{T}_{0, \mathrm{e}, \mathrm{off}}$ & $\left({ }^{\circ} \mathrm{F}\right)$ & Escort & 43.5 & 43.4 & 43.4 & 43.5 & 43.3 & 42.2 & 43.0 & 43.3 & 42.6 \\
\hline $\mathrm{T}_{0, \mathrm{e}, \mathrm{on}}$ & $\left({ }^{\circ} \mathrm{F}\right)$ & Escort & 40.2 & 38.1 & 34.2 & 34.9 & 34.8 & 36.5 & 35.2 & 30.9 & 28.9 \\
\hline$\Delta \mathrm{T}_{0, \mathrm{e}}$ & $\left({ }^{\circ} \mathrm{F}\right)$ & Calc & -3.3 & -5.4 & -9.2 & -8.7 & -8.4 & -5.7 & -7.8 & -12.4 & -13.7 \\
\hline $\mathbf{T}_{\mathrm{s}, \mathbf{e}, \mathbf{o f f}}$ & $\left({ }^{\circ} \mathbf{F}\right)$ & Escort & 37.2 & 37.6 & 37.2 & 37.2 & 37.5 & 35.9 & 36.6 & 36.8 & 36.8 \\
\hline $\mathbf{T}_{\mathrm{s}, \mathrm{e}, \mathrm{on}}$ & $\left({ }^{\circ} \mathbf{F}\right)$ & Calc & 33.9 & 32.2 & 28.0 & 28.5 & 29.1 & 30.2 & 28.8 & 24.4 & 23.1 \\
\hline$\omega_{\mathrm{i}}$ & $\mathrm{gH} 2 \mathrm{O} / \mathrm{kgair}$ & Escort & 0.68 & 0.69 & 0.69 & 0.67 & 0.75 & 1.39 & 1.39 & 1.39 & 1.42 \\
\hline $\mathbf{R H}_{\mathbf{0 , i}}$ & $\%$ & Escort & 9.9 & 9.8 & 10.0 & 9.8 & 10.7 & 10.7 & 10.4 & 10.4 & 10.6 \\
\hline$\omega_{\mathrm{e}, \mathrm{off}}$ & $\mathrm{gH} 2 \mathrm{O} / \mathrm{kgair}$ & Escort & 0.68 & 0.68 & 0.68 & 0.68 & 0.72 & 1.34 & 1.37 & 1.37 & 1.37 \\
\hline$\omega_{\mathrm{e}, \mathrm{on}}$ & $\mathrm{gH} 2 \mathrm{O} / \mathrm{kgair}$ & Escort & 1.39 & 1.93 & 2.78 & 2.78 & 3.05 & 2.70 & 3.09 & 4.19 & 5.02 \\
\hline$\Delta \omega_{\mathrm{e}}$ & $(\mathrm{g} / \mathrm{kg})$ & Calc & 0.71 & 1.25 & 2.09 & 2.10 & 2.32 & 1.36 & 1.73 & 2.82 & 3.65 \\
\hline $\mathbf{R H}_{\mathrm{s}, \mathrm{e}, \mathrm{off}}$ & $\%$ & Escort & 12.2 & 11.9 & 12.1 & 12.1 & 13.1 & 13.0 & 12.7 & 12.5 & 12.8 \\
\hline $\mathbf{R H}_{\mathbf{0 , e , o f f}}$ & $\%$ & Calc & 10.0 & 9.9 & 10.0 & 9.9 & 10.7 & 10.5 & 10.4 & 10.3 & 10.6 \\
\hline RHs,e,on & $\%$ & Calc & 28.3 & 42.1 & 73.3 & 71.5 & 76.2 & 32.8 & 40.2 & 66.8 & 85.0 \\
\hline $\mathbf{R H}_{\mathbf{0 , e}, \mathrm{on}}$ & $\%$ & Calc & 23.0 & 34.7 & 58.1 & 56.6 & 62.1 & 26.4 & 31.8 & 51.3 & 67.2 \\
\hline$\rho_{\mathrm{s}, \mathrm{e}}$ & $(\mathrm{kg} / \mathrm{m} 3)$ & Calc & 1.06 & 1.06 & 1.06 & 1.06 & 1.06 & 0.54 & 0.54 & 0.54 & 0.54 \\
\hline$\Delta \mathrm{GWCe}$ & $(\mathrm{g} / \mathrm{m} 3)$ & Calc & 0.75 & 1.33 & 2.21 & 2.22 & 2.45 & 0.73 & 0.93 & 1.53 & 1.98 \\
\hline $\mathbf{T w b}_{0, \mathrm{e}, \mathbf{o n}}$ & $\left({ }^{\circ} \mathbf{F}\right)$ & Calc & 28.3 & 28.7 & 28.9 & 29.3 & 30.0 & 22.3 & 22.6 & 23.1 & 24.1 \\
\hline $\mathrm{Twb}_{\mathrm{s}, \mathrm{e}, \mathrm{on}}$ & $\left({ }^{\circ} \mathrm{F}\right)$ & Calc & 24.5 & 25.1 & 25.2 & 25.5 & 26.5 & 19.0 & 19.3 & 19.9 & 21.2 \\
\hline $\mathbf{T w b}_{0, \mathrm{e}, \mathrm{off}}$ & $\left({ }^{\circ} \mathbf{F}\right)$ & Calc & 28.2 & 28.2 & 28.2 & 28.2 & 28.2 & 21.8 & 22.2 & 22.3 & 22.0 \\
\hline $\mathrm{Twb}_{\mathrm{s}, \mathrm{e}, \mathrm{off}}$ & $\left({ }^{\circ} \mathrm{F}\right)$ & Calc & 24.4 & 24.6 & 24.4 & 24.4 & 24.7 & 18.5 & 18.8 & 18.9 & 19.0 \\
\hline Nozzle & \# & Target & MOD & MOD & MOD & MOD & MOD & MOD & MOD & MOD & MOD \\
\hline $\mathbf{T}_{\text {water, } \mathbf{i}}$ & $\left({ }^{\circ} \mathrm{F}\right)$ & Target & 45 & 45 & 45 & 45 & 45 & 45 & 45 & 45 & 45 \\
\hline$\tau$ & (s) & Calc & 301 & 300 & 241 & 244 & 244 & 298 & 300 & 242 & 243 \\
\hline$Q_{\text {noz }}$ & (GPM) & Target & 0.49 & 0.89 & 1.98 & 3.07 & 4.34 & 0.49 & 0.89 & 1.98 & 4.34 \\
\hline $\mathbf{P}_{\text {water,noz }}$ & (psid) & Escort & 29.6 & 79.5 & 79.5 & 179.3 & 299.1 & 29.5 & 79.5 & 79.5 & 299.1 \\
\hline $\mathbf{P}_{\text {air,noz }}$ & (psid) & Escort & 15.6 & 30.5 & 30.3 & 60.5 & 60.3 & 15.4 & 30.5 & 30.5 & 60.6 \\
\hline$\Delta P_{n o z}$ & (psid) & Escort & 15.0 & 50.0 & 50.0 & 120.0 & 240.0 & 15.0 & 50.0 & 50.0 & 240.0 \\
\hline $\mathbf{P}_{0} /\left(\mathbf{P}_{0}+\mathbf{P}_{\text {air, noz }}\right)$ & $(-)$ & Calc & 0.46 & 0.30 & 0.30 & 0.17 & 0.17 & 0.30 & 0.18 & 0.18 & 0.10 \\
\hline MVD $_{\mathbf{i}}$ & $(\mu \mathrm{m})$ & Calc & 15 & 15 & 15 & 15 & 19 & 15 & 15 & 15 & 19 \\
\hline TWC $_{\text {bulk }}$ & $(\mathrm{g} / \mathrm{m} 3)$ & Target & 0.6 & 1.0 & 2.2 & 3.5 & 4.9 & 0.6 & 1.0 & 2.3 & 4.9 \\
\hline $\mathbf{T W C}_{\mathrm{m}}$ & $(\mathrm{g} / \mathrm{m} 3)$ & M300 & 0.28 & 0.29 & 1.87 & 3.03 & 6.43 & 0.10 & 0.22 & 1.87 & 4.29 \\
\hline TWC $_{\mathbf{m}, \text { spike }}$ & $(\mathrm{g} / \mathrm{m} 3)$ & M300 & 0.33 & 0.35 & 2.00 & 3.38 & 7.23 & 0.12 & 0.26 & 2.01 & 4.71 \\
\hline $\mathbf{L W C}_{\mathrm{m}, 2.1}$ & $(\mathrm{~g} / \mathrm{m} 3)$ & M300 & 0.22 & 0.04 & 0.18 & 0.27 & 1.29 & 0.02 & 0.04 & 0.13 & 0.36 \\
\hline $\mathbf{L W C}_{\mathrm{m}, \mathbf{0 . 5}}$ & $(\mathrm{g} / \mathrm{m} 3)$ & M300 & 0.21 & 0.05 & 0.18 & 0.30 & 1.14 & 0.03 & 0.04 & 0.15 & 0.34 \\
\hline$\eta_{e}$ & $(-)$ & Calc & 0.79 & 0.16 & 0.10 & 0.10 & 0.20 & 0.27 & 0.19 & 0.08 & 0.08 \\
\hline
\end{tabular}


Table 6. Actual run conditions during two TWC sweeps shown in Table 2.

\begin{tabular}{|c|c|c|c|c|c|c|c|c|c|c|}
\hline Symbol & UNIT & Source & \multicolumn{8}{|c|}{ DATA } \\
\hline Test & \# & $\log$ & 670 & 671 & 672 & 673 & 677 & 676 & 675 & 674 \\
\hline Ice Accretion & $(\mathrm{Y} / \mathrm{N})$ & Notes & $\mathrm{Y}+$ & $\mathrm{Y}+$ & $\mathrm{Y}$ & $\mathrm{Y}$ & $\mathrm{Y}+$ & $\mathrm{Y}+$ & $\mathrm{Y}$ & Y \\
\hline Altitude & $(\mathrm{kft})$ & $\log$ & 5.32 & 5.34 & 5.34 & 5.36 & 5.35 & 5.34 & 5.34 & 5.34 \\
\hline $\mathbf{P}_{0}$ & (psi) & $\log$ & 12.66 & 12.65 & 12.66 & 12.65 & 12.65 & 12.65 & 12.65 & 12.65 \\
\hline $\mathbf{P}_{\text {tank }}$ & (psi) & Log & 12.07 & 12.07 & 12.07 & 12.06 & 12.06 & 12.07 & 12.07 & 12.07 \\
\hline $\mathrm{P}_{\mathrm{s}, \mathrm{e}}$ & (psi) & Escort & 12.1 & 12.1 & 12.1 & 12.1 & 12.1 & 12.1 & 12.1 & 12.1 \\
\hline $\mathrm{M}_{\mathrm{e}}$ & $(-)$ & Escort & 0.25 & 0.25 & 0.25 & 0.25 & 0.25 & 0.25 & 0.25 & 0.25 \\
\hline$v_{e}$ & $(\mathrm{~m} / \mathrm{s})$ & Escort & 84.9 & 84.9 & 84.9 & 84.9 & 84.9 & 84.9 & 84.9 & 83.3 \\
\hline $\mathbf{T}_{\mathbf{0}}$ & $\left({ }^{\circ} \mathbf{F}\right)$ & Escort & 39.4 & 39.1 & 39.6 & 39.6 & 35.3 & 34.6 & 35.0 & 35.0 \\
\hline $\mathrm{T}_{0, \mathrm{e}, \mathrm{off}}$ & $\left({ }^{\circ} \mathrm{F}\right)$ & Escort & 39.7 & 38.7 & 38.5 & 37.9 & 35.5 & 34.2 & 33.6 & 35.1 \\
\hline $\mathrm{T}_{0, \mathrm{e}, \mathrm{on}}$ & $\left({ }^{\circ} \mathrm{F}\right)$ & Escort & 36.7 & 34.6 & 33.3 & 31.2 & 32.3 & 30.3 & 30.4 & 28.2 \\
\hline$\Delta \mathrm{T}_{0, \mathrm{e}}$ & $\left({ }^{\circ} \mathrm{F}\right)$ & Calc & -3.0 & -4.1 & -5.2 & -6.7 & -3.1 & -3.9 & -3.2 & -6.9 \\
\hline $\mathbf{T}_{\mathrm{s}, \mathrm{e}, \mathrm{off}}$ & $\left({ }^{\circ} \mathbf{F}\right)$ & Escort & 33.1 & 32.9 & 33.3 & 33.3 & 29.0 & 28.4 & 28.7 & 28.7 \\
\hline $\mathbf{T}_{\mathrm{s}, \mathrm{e}, \mathrm{on}}$ & $\left({ }^{\circ} \mathbf{F}\right)$ & Calc & 30.0 & 28.8 & 28.1 & 26.6 & 25.9 & 24.6 & 25.5 & 21.8 \\
\hline$\omega_{\mathrm{i}}$ & gH2O/kgair & Escort & 0.64 & 0.65 & 0.64 & 0.63 & 0.49 & 0.47 & 0.47 & 0.47 \\
\hline $\mathbf{R H}_{\mathbf{0 , i}}$ & $\%$ & Escort & 10.9 & 11.2 & 10.8 & 10.7 & 9.8 & 9.8 & 9.6 & 9.7 \\
\hline$\omega_{e, o f f}$ & $\mathrm{gH} 2 \mathrm{O} / \mathrm{kg}$ air & Escort & 0.64 & 0.65 & 0.71 & 0.69 & 0.49 & 0.52 & 0.52 & 0.48 \\
\hline$\omega_{\mathrm{e}, \mathrm{on}}$ & $\mathrm{gH} 2 \mathrm{O} / \mathrm{kg}$ air & Escort & 1.19 & 1.52 & 2.05 & 2.96 & 0.98 & 1.37 & 1.85 & 2.54 \\
\hline$\Delta \omega_{\mathrm{e}}$ & $(\mathrm{g} / \mathrm{kg})$ & Calc & 0.55 & 0.87 & 1.34 & 2.26 & 0.49 & 0.85 & 1.33 & 2.06 \\
\hline $\mathbf{R H}_{\mathrm{s}, \mathrm{e}, \mathrm{off}}$ & $\%$ & Escort & 13.4 & 13.9 & 14.6 & 14.5 & 12.2 & 13.3 & 13.7 & 12.0 \\
\hline $\mathbf{R H}_{\mathbf{0 , e , o f f}}$ & $\%$ & Calc & 10.8 & 11.4 & 12.5 & 12.5 & 9.8 & 10.8 & 11.2 & 9.6 \\
\hline RHs,e,on & $\%$ & Calc & 28.6 & 38.6 & 53.7 & 83.1 & 28.4 & 42.5 & 54.9 & 89.5 \\
\hline $\mathbf{R H}_{\mathbf{0 , e , o n}}$ & $\%$ & Calc & 22.6 & 31.3 & 44.4 & 70.0 & 22.0 & 33.9 & 45.6 & 69.2 \\
\hline$\rho_{s, e}$ & $(\mathrm{~kg} / \mathrm{m} 3)$ & Calc & 1.06 & 1.06 & 1.06 & 1.06 & 1.07 & 1.07 & 1.07 & 1.07 \\
\hline$\Delta \mathrm{GWCe}$ & $(\mathrm{g} / \mathrm{m} 3)$ & Calc & 0.59 & 0.92 & 1.43 & 2.41 & 0.52 & 0.92 & 1.43 & 2.21 \\
\hline $\mathbf{T w b}_{\mathbf{0}, \mathrm{e}, \mathbf{o n}}$ & $\left({ }^{\circ} \mathbf{F}\right)$ & Calc & 25.9 & 25.6 & 26.5 & 27.8 & 22.8 & 22.8 & 24.3 & 25.0 \\
\hline $\mathrm{Twb}_{\mathrm{s}, \mathrm{e}, \mathrm{on}}$ & $\left({ }^{\circ} \mathrm{F}\right)$ & Calc & 21.7 & 21.9 & 23.1 & 24.9 & 18.5 & 19.0 & 21.0 & 20.9 \\
\hline $\mathbf{T w b}_{\mathbf{0}, \mathrm{e}, \mathrm{off}}$ & $\left({ }^{\circ} \mathbf{F}\right)$ & Calc & 26.1 & 25.5 & 25.6 & 25.2 & 23.2 & 22.5 & 22.2 & 22.9 \\
\hline $\mathrm{Twb}_{\mathrm{s}, \mathrm{e}, \mathrm{off}}$ & $\left({ }^{\circ} \mathrm{F}\right)$ & Calc & 21.8 & 21.8 & 22.2 & 22.2 & 18.9 & 18.7 & 18.9 & 18.7 \\
\hline Nozzle & \# & Target & MOD & MOD & MOD & MOD & MOD & MOD & MOD & MOD \\
\hline $\mathbf{T}_{\text {water, } \mathbf{i}}$ & $\left({ }^{\circ} \mathrm{F}\right)$ & Target & 45 & 45 & 45 & 45 & 45 & 45 & 45 & 45 \\
\hline$\tau$ & (s) & Calc & 299 & 300 & 300 & 300 & 242 & 190 & 300 & 299 \\
\hline$Q_{\text {noz }}$ & (GPM) & Target & 0.69 & 1.20 & 1.99 & 4.43 & 0.69 & 1.20 & 1.99 & 4.43 \\
\hline $\mathbf{P}_{\text {water,noz }}$ & (psid) & Escort & 37.6 & 104.5 & 279.1 & 279.1 & 37.6 & 104.5 & 279.1 & 279.1 \\
\hline $\mathbf{P}_{\text {air,noz }}$ & (psid) & Escort & 8.5 & 15.5 & 30.4 & 30.5 & 8.5 & 15.5 & 30.3 & 30.5 \\
\hline$\Delta P_{n o z}$ & (psid) & Escort & 30.0 & 90.0 & 250.0 & 250.0 & 30.0 & 90.0 & 250.0 & 250.0 \\
\hline $\mathbf{P}_{0} /\left(\mathbf{P}_{0}+\mathbf{P}_{\text {air, noz }}\right)$ & $(-)$ & Calc & 0.61 & 0.46 & 0.30 & 0.30 & 0.61 & 0.46 & 0.30 & 0.30 \\
\hline MVD $_{\mathbf{i}}$ & $(\mu \mathrm{m})$ & Calc & 35 & 39 & 38 & 38 & 36 & 39 & 39 & 38 \\
\hline TWC $_{\text {bulk }}$ & $(\mathrm{g} / \mathrm{m} 3)$ & Target & 0.8 & 1.4 & 2.3 & 5.0 & 0.8 & 1.4 & 2.3 & 5.1 \\
\hline $\mathbf{T W C}_{\mathrm{m}}$ & $(\mathrm{g} / \mathrm{m} 3)$ & M300 & 1.38 & 2.85 & 4.31 & 10.01 & 1.50 & 3.31 & 3.63 & 9.62 \\
\hline TWC $_{m, \text { spike }}$ & $(\mathrm{g} / \mathrm{m} 3)$ & M300 & 1.60 & 3.38 & 4.96 & 10.91 & 1.76 & 3.89 & 4.03 & 10.42 \\
\hline $\mathrm{LWC}_{\mathrm{m}, 2.1}$ & $(\mathrm{~g} / \mathrm{m} 3)$ & M300 & 0.96 & 1.90 & 0.99 & 2.72 & 1.06 & 2.22 & 0.70 & 1.92 \\
\hline $\mathbf{L W C}_{\mathrm{m}, 0.5}$ & $(\mathrm{~g} / \mathrm{m} 3)$ & M300 & 0.76 & 1.46 & 0.76 & 1.96 & 0.83 & 1.70 & 0.57 & 1.44 \\
\hline$\eta_{\mathrm{e}}$ & $(-)$ & Calc & 0.69 & 0.66 & 0.23 & 0.27 & 0.70 & 0.67 & 0.19 & 0.20 \\
\hline
\end{tabular}


Table 7. Actual run conditions during three RH Sweeps shown in Table 3.

\begin{tabular}{|c|c|c|c|c|c|c|c|c|c|c|c|}
\hline Symbol & UNIT & Source & \multicolumn{9}{|c|}{ DATA } \\
\hline Test & \# & Log & 667 & 668 & 669 & 684 & 685 & 686 & 681 & 682 & 683 \\
\hline Ice Accretion & $(\mathrm{Y} / \mathrm{N})$ & Notes & $\mathrm{N}$ & $\mathrm{N}$ & $\mathrm{N}$ & $\mathrm{N}$ & $\mathrm{Y}$ & $\mathrm{N}$ & Y- & $\mathrm{Y}$ & $\mathrm{N}$ \\
\hline Altitude & $(\mathrm{kft})$ & $\log$ & 5.34 & 5.34 & 5.35 & 23.82 & 23.77 & 23.77 & 22.20 & 22.19 & 22.19 \\
\hline $\mathbf{P}_{\mathbf{0}}$ & (psi) & Log & 12.64 & 12.64 & 12.64 & 6.45 & 6.47 & 6.45 & 6.46 & 6.46 & 6.47 \\
\hline $\mathbf{P}_{\text {tank }}$ & (psi) & $\log$ & 12.06 & 12.06 & 12.06 & 5.74 & 5.75 & 5.76 & 6.15 & 6.16 & 6.16 \\
\hline $\mathrm{P}_{\mathrm{s}, \mathrm{e}}$ & (psi) & Escort & 12.1 & 12.1 & 12.1 & 5.8 & 5.8 & 5.8 & 6.2 & 6.2 & 6.2 \\
\hline $\mathrm{M}_{\mathrm{e}}$ & $(-)$ & Escort & 0.25 & 0.25 & 0.25 & 0.40 & 0.39 & 0.39 & 0.26 & 0.26 & 0.26 \\
\hline$v_{e}$ & $(\mathrm{~m} / \mathrm{s})$ & Escort & 85.0 & 85.0 & 85.0 & 133.8 & 133.8 & 129.1 & 84.5 & 86.4 & 86.4 \\
\hline $\mathbf{T}_{\mathbf{0}}$ & $\left({ }^{\circ} \mathbf{F}\right)$ & Escort & 44.0 & 44.1 & 43.8 & 47.4 & 47.7 & 46.8 & 43.3 & 43.6 & 44.7 \\
\hline $\mathrm{T}_{0, \mathrm{e}, \mathrm{off}}$ & $\left({ }^{\circ} \mathrm{F}\right)$ & Escort & 43.4 & 44.1 & 43.6 & 45.9 & 46.1 & 43.0 & 42.6 & 42.6 & 43.0 \\
\hline $\mathrm{T}_{0, \mathrm{e}, \mathrm{on}}$ & $\left({ }^{\circ} \mathrm{F}\right)$ & Escort & 38.1 & 38.5 & 39.3 & 33.8 & 35.8 & 36.1 & 28.9 & 32.1 & 35.5 \\
\hline$\Delta \mathrm{T}_{0, \mathrm{e}}$ & $\left({ }^{\circ} \mathrm{F}\right)$ & Calc & -5.4 & -5.7 & -4.3 & -12.1 & -10.3 & -6.8 & -13.7 & -10.6 & -7.5 \\
\hline $\mathbf{T}_{\mathrm{s}, \mathbf{e}, \mathbf{o f f}}$ & $\left({ }^{\circ} \mathbf{F}\right)$ & Escort & 37.6 & 37.7 & 37.3 & 31.6 & 32.5 & 32.0 & 36.8 & 36.9 & 38.0 \\
\hline $\mathbf{T}_{\mathrm{s}, \mathrm{e}, \mathrm{on}}$ & $\left({ }^{\circ} \mathbf{F}\right)$ & Calc & 32.2 & 32.0 & 33.0 & 19.6 & 22.2 & 25.2 & 23.1 & 26.3 & 30.6 \\
\hline$\omega_{i}$ & $\mathrm{gH} 2 \mathrm{O} / \mathrm{kg}$ air & Escort & 0.69 & 2.50 & 3.47 & 1.46 & 4.91 & 7.51 & 1.42 & 3.29 & 7.01 \\
\hline $\mathbf{R H}_{\mathbf{0 , i}}$ & $\%$ & Escort & 9.8 & 35.6 & 49.8 & 9.4 & 31.0 & 48.9 & 10.6 & 24.4 & 49.5 \\
\hline$\omega_{\mathrm{e}, \mathrm{off}}$ & gH2O/kgair & Escort & 0.68 & 2.42 & 3.32 & 1.44 & 4.51 & 6.83 & 1.37 & 3.12 & 6.35 \\
\hline$\omega_{\mathrm{e}, \mathbf{o n}}$ & $\mathrm{gH} 2 \mathrm{O} / \mathrm{kgair}$ & Escort & 1.93 & 3.41 & 4.16 & 4.66 & 6.90 & 8.50 & 5.02 & 6.19 & 8.23 \\
\hline$\Delta \omega_{\mathrm{e}}$ & $(\mathrm{g} / \mathrm{kg})$ & Calc & 1.3 & 0.99 & 0.83 & 3.2 & 2.4 & 1.7 & 3.6 & 3.1 & 1.9 \\
\hline $\mathbf{R H}_{\mathrm{s}, \mathrm{e}, \mathbf{o f f}}$ & $\%$ & Escort & 11.9 & 41.6 & 58.5 & 15.6 & 47.1 & 73.9 & 12.8 & 28.6 & 56.1 \\
\hline $\mathbf{R H}_{\mathbf{0 , e , o f f}}$ & $\%$ & Calc & 9.9 & 34.3 & 48.0 & 9.7 & 30.3 & 51.3 & 10.6 & 23.9 & 47.9 \\
\hline RHs,e,on & $\%$ & Calc & 42.1 & 74.4 & 87.3 & 87.2 & 113.6 & 120.9 & 85.0 & 89.3 & 97.2 \\
\hline $\mathbf{R H}_{\mathbf{0 , e , o n}}$ & $\%$ & Calc & 34.7 & 60.2 & 70.9 & 50.4 & 68.9 & 83.2 & 67.2 & 71.6 & 82.8 \\
\hline$\rho_{s, e}$ & $(\mathrm{~kg} / \mathrm{m} 3)$ & Calc & 1.06 & 1.05 & 1.06 & 0.51 & 0.51 & 0.51 & 0.54 & 0.54 & 0.54 \\
\hline$\Delta \mathrm{GWCe}$ & $(\mathrm{g} / \mathrm{m} 3)$ & Calc & 1.33 & 1.04 & 0.88 & 1.65 & 1.22 & 0.86 & 1.98 & 1.65 & 1.01 \\
\hline$T w b_{0, e, o n}$ & $\left({ }^{\circ} \mathbf{F}\right)$ & Calc & 28.7 & 32.7 & 35.1 & 25.2 & 30.2 & 33.1 & 24.1 & 27.6 & 32.4 \\
\hline $\mathrm{Twb}_{\mathrm{s}, \mathrm{e}, \mathrm{on}}$ & $\left({ }^{\circ} \mathrm{F}\right)$ & Calc & 25.1 & 29.0 & 31.4 & 18.0 & 23.9 & 27.9 & 21.2 & 24.8 & 30.1 \\
\hline $\mathbf{T w b}_{0, \mathrm{e}, \mathrm{off}}$ & $\left({ }^{\circ} \mathbf{F}\right)$ & Calc & 28.2 & 33.0 & 35.1 & 23.5 & 29.5 & 32.4 & 22.0 & 25.6 & 31.6 \\
\hline $\mathrm{Twb}_{\mathrm{s}, \mathrm{e}, \mathrm{off}}$ & $\left({ }^{\circ} \mathrm{F}\right)$ & Calc & 24.6 & 29.2 & 31.4 & 16.0 & 23.2 & 27.7 & 19.0 & 22.7 & 29.5 \\
\hline Nozzle & \# & Target & MOD & MOD & MOD & MOD & MOD & MOD & MOD & MOD & MOD \\
\hline $\mathbf{T}_{\text {water, } \mathbf{i}}$ & $\left({ }^{\circ} \mathrm{F}\right)$ & Target & 45 & 45 & 45 & 45 & 45 & 45 & 45 & 45 & 45 \\
\hline$\tau$ & (s) & Calc & 300 & 243 & 300 & 300 & 208 & 246 & 243 & 261 & 248 \\
\hline $\mathbf{Q}_{\text {noz }}$ & (GPM) & Target & 0.89 & 0.89 & 0.89 & 4.34 & 4.34 & 4.34 & 4.34 & 4.34 & 4.34 \\
\hline $\mathbf{P}_{\text {water,noz }}$ & (psid) & Escort & 79.5 & 79.5 & 79.6 & 299.0 & 299.1 & 299.1 & 299.1 & 299.1 & 299.1 \\
\hline $\mathbf{P}_{\text {air,noz }}$ & (psid) & Escort & 30.5 & 30.4 & 30.3 & 60.4 & 60.5 & 60.3 & 60.6 & 60.7 & 60.5 \\
\hline$\Delta P_{n o z}$ & (psid) & Escort & 50.0 & 50.0 & 50.0 & 240.0 & 240.0 & 240.0 & 240.0 & 240.0 & 240.0 \\
\hline $\mathbf{P}_{0} /\left(\mathbf{P}_{0}+\mathbf{P}_{\text {air, noz }}\right)$ & $(-)$ & Calc & 0.30 & 0.30 & 0.30 & 0.10 & 0.10 & 0.10 & 0.10 & 0.10 & 0.10 \\
\hline MVD $_{i}$ & $(\mu \mathrm{m})$ & Calc & 15 & 15 & 15 & 19 & 19 & 19 & 19 & 19 & 19 \\
\hline TWC $_{\text {bulk }}$ & $(\mathrm{g} / \mathrm{m} 3)$ & Target & 1.0 & 1.0 & 1.0 & 3.09 & 3.09 & 3.18 & 4.9 & 4.9 & 4.9 \\
\hline $\mathbf{T W C}_{\mathrm{m}}$ & $(\mathrm{g} / \mathrm{m} 3)$ & M300 & 0.29 & 0.88 & 1.14 & 3.67 & 4.52 & 4.85 & 4.29 & 4.90 & 5.34 \\
\hline TWC $_{\mathrm{m} \text {,spike }}$ & $(\mathrm{g} / \mathrm{m} 3)$ & M300 & 0.35 & 0.98 & 1.25 & 3.90 & 4.91 & 5.23 & 4.71 & 5.62 & 5.92 \\
\hline $\mathbf{L W C}_{\mathrm{m}, 2.1}$ & $(\mathrm{~g} / \mathrm{m} 3)$ & M300 & 0.04 & 0.71 & 0.93 & 0.52 & 2.05 & 3.42 & 0.36 & 0.53 & 3.96 \\
\hline $\mathrm{LWC}_{\mathrm{m}, 0.5}$ & $(\mathrm{~g} / \mathrm{m} 3)$ & M300 & 0.05 & 0.63 & 0.83 & 0.55 & 1.75 & 2.85 & 0.34 & 0.49 & 3.46 \\
\hline$\eta_{\mathrm{e}}$ & $(-)$ & Calc & 0.16 & 0.81 & 0.82 & 0.15 & 0.45 & 0.70 & 0.08 & 0.11 & 0.74 \\
\hline
\end{tabular}


Table 8. Actual run conditions during four spray bar temperature sweeps shown in Table 4.

\begin{tabular}{|c|c|c|c|c|c|c|c|c|c|c|c|c|c|}
\hline Symbol & UNIT & Source & \multicolumn{11}{|c|}{ DATA } \\
\hline Test & $\#$ & $\log$ & 667 & 690 & 691 & 689 & 692 & 679 & 688 & 693 & 680 & 687 & 694 \\
\hline Ice Accretion & $(\mathrm{Y} / \mathrm{N})$ & Notes & $\mathrm{N}$ & $\mathrm{Y}-$ & $\mathrm{Y}$ & $\mathrm{Y}$ & $\mathrm{Y}$ & $\mathrm{N}$ & $\mathrm{Y}-$ & Y- & $\mathrm{N}$ & $\mathrm{Y}$ & $\mathrm{Y}$ \\
\hline Altitude & $(\mathrm{kft})$ & Log & 5.34 & 5.36 & 5.34 & 5.33 & 5.35 & 22.16 & 22.16 & 22.17 & 22.16 & 22.22 & 22.15 \\
\hline $\mathbf{P}_{\mathbf{0}}$ & (psi) & Log & 12.64 & 12.64 & 12.65 & 12.67 & 12.64 & 6.47 & 6.47 & 6.46 & 6.46 & 6.47 & 6.47 \\
\hline $\mathbf{P}_{\text {tank }}$ & (psi) & $\log$ & 12.06 & 12.06 & 12.06 & 12.07 & 12.06 & 6.16 & 6.16 & 6.17 & 6.16 & 6.16 & 6.17 \\
\hline $\mathrm{P}_{\mathrm{s}, \mathrm{e}}$ & (psi) & Escort & 12.1 & 12.1 & 12.1 & 12.1 & 12.1 & 6.2 & 6.2 & 6.2 & 6.2 & 6.2 & 6.2 \\
\hline $\mathrm{M}_{\mathrm{e}}$ & $(-)$ & Escort & 0.25 & 0.25 & 0.25 & 0.25 & 0.25 & 0.26 & 0.26 & 0.25 & 0.26 & 0.26 & 0.25 \\
\hline$v_{e}$ & $(\mathrm{~m} / \mathrm{s})$ & Escort & 85.0 & 83.3 & 85.0 & 85.0 & 85.0 & 84.5 & 85.9 & 84.5 & 84.5 & 85.9 & 84.5 \\
\hline $\mathbf{T}_{\mathbf{0}}$ & $\left({ }^{\circ} \mathbf{F}\right)$ & Escort & 44.0 & 42.9 & 42.9 & 42.6 & 43.0 & 43.3 & 42.7 & 42.1 & 43.4 & 42.8 & 43.7 \\
\hline $\mathrm{T}_{0, \mathrm{e}, \mathrm{off}}$ & $\left({ }^{\circ} \mathrm{F}\right)$ & Escort & 43.4 & 42.3 & 43.8 & 42.7 & 43.2 & 43.0 & 41.7 & 44.7 & 43.3 & 43.6 & 43.9 \\
\hline $\mathrm{T}_{0, \mathrm{e}, \mathrm{on}}$ & $\left({ }^{\circ} \mathrm{F}\right)$ & Escort & 38.1 & 36.8 & 37.7 & 39.4 & 39.9 & 35.2 & 34.3 & 35.7 & 30.9 & 29.8 & 30.9 \\
\hline$\Delta \mathrm{T}_{0, \mathrm{e}}$ & $\left({ }^{\circ} \mathrm{F}\right)$ & Calc & -5.4 & -5.5 & -6.0 & -3.3 & -3.3 & -7.8 & -7.4 & -8.9 & -12.4 & -13.8 & -13.0 \\
\hline $\mathbf{T}_{\mathrm{s}, \mathbf{e}, \mathbf{o f f}}$ & $\left({ }^{\circ} \mathbf{F}\right)$ & Escort & 37.6 & 36.5 & 36.4 & 36.2 & 36.5 & 36.6 & 36.1 & 35.6 & 36.8 & 36.4 & 37.5 \\
\hline $\mathbf{T}_{\mathrm{s}, \mathrm{e}, \mathrm{on}}$ & $\left({ }^{\circ} \mathbf{F}\right)$ & Calc & 32.2 & 31.1 & 30.4 & 32.9 & 33.2 & 28.8 & 28.6 & 26.8 & 24.4 & 22.6 & 24.4 \\
\hline$\omega_{\mathrm{i}}$ & $\mathrm{gH} 2 \mathrm{O} / \mathrm{kgair}$ & Escort & 0.69 & 0.70 & 0.71 & 0.68 & 0.74 & 1.39 & 1.20 & 1.27 & 1.39 & 1.21 & 1.06 \\
\hline $\mathbf{R H}_{\mathbf{0 , i}}$ & $\%$ & Escort & 9.8 & 10.5 & 10.6 & 10.2 & 11.0 & 10.4 & 9.2 & 10.0 & 10.4 & 9.2 & 7.9 \\
\hline$\omega_{\mathrm{e}, \mathrm{off}}$ & $\mathrm{gH} 2 \mathrm{O} / \mathrm{kgair}$ & Escort & 0.68 & 0.77 & 0.71 & 0.67 & 0.73 & 1.37 & 1.31 & 1.29 & 1.37 & 1.21 & 1.30 \\
\hline$\omega_{\mathrm{e}, \mathrm{on}}$ & $\mathrm{gH} 2 \mathrm{O} / \mathrm{kgair}$ & Escort & 1.93 & 2.07 & 2.15 & 1.36 & 1.47 & 3.09 & 3.20 & 3.31 & 4.19 & 4.43 & 4.86 \\
\hline$\Delta \omega_{\mathrm{e}}$ & $(\mathrm{g} / \mathrm{kg})$ & Calc & 1.25 & 1.30 & 1.43 & 0.69 & 0.73 & 1.73 & 1.89 & 2.02 & 2.82 & 3.21 & 3.56 \\
\hline $\mathbf{R H}_{\mathrm{s}, \mathrm{e}, \mathrm{off}}$ & $\%$ & Escort & 11.9 & 14.0 & 13.0 & 12.5 & 13.4 & 12.7 & 12.5 & 12.2 & 12.5 & 11.5 & 12.1 \\
\hline $\mathbf{R H}_{\mathbf{0 , e , o f f}}$ & $\%$ & Calc & 9.9 & 11.7 & 10.3 & 10.1 & 10.8 & 10.4 & 10.5 & 9.2 & 10.3 & 9.0 & 9.6 \\
\hline RHs,e,on & $\%$ & Calc & 42.1 & 47.2 & 50.7 & 28.7 & 30.7 & 40.2 & 41.9 & 47.3 & 67 & 77 & 77 \\
\hline $\mathbf{R H}_{\mathbf{0 , e , o n}}$ & $\%$ & Calc & 34.7 & 39.0 & 39.1 & 23.2 & 24.5 & 31.8 & 34.2 & 33.2 & 51.3 & 56.9 & 59.6 \\
\hline$\rho_{\mathrm{s}, \mathrm{e}}$ & $(\mathrm{kg} / \mathrm{m} 3)$ & Calc & 1.06 & 1.05 & 1.06 & 1.06 & 1.06 & 0.54 & 0.54 & 0.54 & 0.54 & 0.54 & 0.54 \\
\hline$\Delta \mathrm{GWCe}$ & $(\mathrm{g} / \mathrm{m} 3)$ & Calc & 1.33 & 1.37 & 1.52 & 0.72 & 0.77 & 0.93 & 1.02 & 1.09 & 1.53 & 1.74 & 1.93 \\
\hline $\mathbf{T w b}_{0, \mathrm{e}, \mathrm{on}}$ & $\left({ }^{\circ} \mathbf{F}\right)$ & Calc & 28.7 & 28.4 & 29.1 & 27.9 & 28.4 & 22.6 & 22.4 & 23.2 & 23.1 & 23.2 & 24.5 \\
\hline $\mathrm{Twb}_{\mathrm{s}, \mathrm{e}, \mathrm{on}}$ & $\left({ }^{\circ} \mathrm{F}\right)$ & Calc & 25.1 & 24.8 & 24.7 & 23.8 & 24.4 & 19.3 & 19.5 & 18.9 & 19.9 & 19.6 & 21.4 \\
\hline $\mathbf{T w b}_{0, \mathrm{e}, \mathrm{off}}$ & $\left({ }^{\circ} \mathbf{F}\right)$ & Calc & 28.2 & 27.8 & 28.4 & 27.8 & 28.2 & 22.2 & 21.5 & 22.7 & 22.3 & 22.1 & 22.4 \\
\hline $\mathrm{Twb}_{\mathrm{s}, \mathrm{e}, \mathrm{off}}$ & $\left({ }^{\circ} \mathrm{F}\right)$ & Calc & 24.6 & 24.2 & 24.0 & 23.8 & 24.1 & 18.8 & 18.5 & 18.2 & 18.9 & 18.4 & 19.2 \\
\hline Nozzle & \# & Target & MOD & MOD & MOD & MOD & MOD & MOD & MOD & MOD & MOD & MOD & MOD \\
\hline $\mathbf{T}_{\text {water, } \mathbf{i}}$ & $\left({ }^{\circ} \mathrm{F}\right)$ & Target & 45 & 110 & 180 & 110 & 180 & 45 & 110 & 180 & 45 & 110 & 180 \\
\hline$\tau$ & (s) & Calc & 300 & 257 & 299 & 299 & 299 & 300 & 253 & 279 & 242 & 261 & 299 \\
\hline $\mathbf{Q}_{\text {noz }}$ & (GPM) & Target & 0.89 & 0.89 & 0.89 & 0.69 & 0.69 & 0.89 & 0.89 & 0.89 & 1.98 & 1.98 & 1.98 \\
\hline $\mathbf{P}_{\text {water,noz }}$ & (psid) & Escort & 79.5 & 79.7 & 80.5 & 37.8 & 38.5 & 79.5 & 79.7 & 80.5 & 79.5 & 79.6 & 80.5 \\
\hline $\mathbf{P}_{\mathrm{air}, \mathrm{noz}}$ & (psid) & Escort & 30.5 & 30.4 & 30.4 & 8.5 & 8.6 & 30.5 & 30.4 & 30.5 & 30.5 & 30.5 & 35.3 \\
\hline$\Delta P_{n o z}$ & (psid) & Escort & 50.0 & 50.0 & 50.0 & 30.0 & 30.0 & 50.0 & 50.0 & 50.0 & 50.0 & 50.0 & 50.0 \\
\hline $\mathbf{P}_{0} /\left(\mathbf{P}_{0}+\mathbf{P}_{\text {air, noz }}\right)$ & $(-)$ & Calc & 0.30 & 0.30 & 0.30 & 0.61 & 0.61 & 0.18 & 0.18 & 0.18 & 0.18 & 0.18 & 0.18 \\
\hline MVDi $_{i}$ & $(\mu \mathrm{m})$ & Calc & 15 & 15 & 15 & 36 & 36 & 15 & 15 & 15 & 15 & 15 & 14 \\
\hline TWC $_{\text {bulk }}$ & $(\mathrm{g} / \mathrm{m} 3)$ & Target & 1.0 & 1.0 & 1.0 & 0.8 & 0.8 & 1.0 & 1.0 & 1.0 & 2.3 & 2.3 & 2.3 \\
\hline $\mathbf{T W C}_{\mathrm{m}}$ & $(\mathrm{g} / \mathrm{m} 3)$ & M300 & 0.29 & 0.51 & 0.42 & 1.29 & 1.22 & 0.22 & 0.29 & 0.25 & 1.87 & 1.68 & 1.40 \\
\hline TWC $_{\text {m,spike }}$ & (g/m3) & M300 & 0.35 & 0.56 & 0.47 & 1.46 & 1.41 & 0.26 & 0.34 & 0.28 & 2.01 & 1.84 & 1.55 \\
\hline $\mathbf{L W C}_{\mathbf{m}, \mathbf{2 . 1}}$ & $(\mathrm{g} / \mathrm{m} 3)$ & M300 & 0.04 & 0.42 & 0.35 & 0.90 & 0.83 & 0.04 & 0.22 & 0.21 & 0.13 & 0.99 & 1.19 \\
\hline $\mathbf{L W C}_{\mathrm{m}, 0.5}$ & $(\mathrm{~g} / \mathrm{m} 3)$ & M300 & 0.05 & 0.38 & 0.31 & 0.71 & 0.65 & 0.04 & 0.20 & 0.20 & 0.15 & 1.01 & 1.21 \\
\hline$\eta_{\mathrm{e}}$ & $(-)$ & Calc & 0.16 & 0.83 & 0.83 & 0.70 & 0.68 & 0.19 & 0.73 & 0.86 & 0.08 & 0.60 & 0.87 \\
\hline
\end{tabular}




\section{Acknowledgments}

The authors wish to acknowledge the financial support for this work by the Advanced Aircraft Icing (AAI) Subproject of the NASA Advance Air Transport Technology Project (AATT) under NASA's, Advanced Air Vehicle's program. The authors would like to thank Mr. Chris Lynch for his excellent imaging work during the experiment.

\section{References}

${ }^{1}$ Griffin, T. A., Lizanich, P., and Dicki, D. J. "PSL Icing Facility Upgrade Overview," 6th AIAA Atmospheric and Space Environments Conference, AIAA-2014-2896, 2014.

${ }^{2}$ Oliver, M. J. "Validation Ice Crystal Icing Engine Test in the Propulsion Systems Laboratory at NASA Glenn Research Center," 6th AIAA Atmospheric and Space Environments Conference, AIAA-2014-2898, 2014.

${ }^{3}$ Oliver, M. J. "Validation ice crystal icing engine test in the propulsion systems laboratory at NASA glenn research center," Transactions of Japanese Society for Medical and Biological Engineering Vol. 51, No. SUPPL., 2013.

${ }^{4}$ Flegel, A. B., and Oliver, M. J. "Preliminary Results from a Heavily Instrumented Engine Ice Crystal Icing Test in a Ground Based Altitude Test Facility," 8th AIAA Atmospheric and Space Environments Conference, AIAA Aviation and Aeronautics Forum and Exposition 2016, American Institute of Aeronautics and Astronautics, Washington, D.C. (submitted for publication).

${ }^{5}$ Struk, P. M., Bencic, T., Tsao, J. C., Fuleki, D., and Knezevici, D. C. "Preparation for scaling studies of icecrystal icing at the NRC research altitude test facility," 5th AIAA Atmospheric and Space Environments Conference. 2013.

${ }^{6}$ Currie, T. C., Struk, P. M., Tsao, J. C., Fuleki, D., and Knezevici, D. C. "Fundamental study of mixed-phase icing with application to ice crystal accretion in aircraft jet engines," 4th AIAA Atmospheric and Space Environments Conference 2012. 2012.

${ }^{7}$ Struk, P., Currie, T., Wright, W. B., Knezevici, D. C., Fuleki, D., Broeren, A., Vargas, M., and Tsao, J. "Fundamental Ice Crystal Accretion Physics Studies," SAE 2011 International Conference on Aircraft and Engine Icing and Ground Deicing, SAE Technical Paper 2011-38-0018 or NASA/TM-2012-217429, 2011.

${ }^{8}$ Vargas, M., Struk, P. M., Kreeger, R. E., Palacios, J., Iyer, K., and Gold, R. E. "Ice Particle Impacts on a Moving Wedge," 6th AIAA Atmospheric and Space Environments Conference, AIAA-2014-3045, 2014.

${ }^{9}$ Hauk, T., Roisman, I. V., and Tropea, C. D. "Investigation of the Impact Behaviour of Ice Particles," 6th AIAA Atmospheric and Space Environments Conference, AIAA-2014-3046, 2014.

${ }^{10}$ Hauk, T., Bonaccurso, E., Roisman, I. V., and Tropea, C. "Ice crystal impact onto a dry solid wall. Particle fragmentation," Proceedings of the Royal Society of London A: Mathematical, Physical and Engineering Sciences Vol. 471, No. 2181, 2015.

${ }^{11}$ Feulner, M., Liao, S., Rose, B., and Liu, X. "Ice Crystal Ingestion in a Turbofan Engine," SAE 2015 International Conference on Icing of Aircraft, Engines, and Structures, SAE Technical Paper 2015-01-2146, 2015.

${ }^{12}$ Fuleki, D. M., and MacLeod, J. D. "Ice Crystal Accretion Test Rig Development For A Compressor Transition Duct," AIAA Guidance, Navigation, and Control Conference, AIAA 2010-7529, 2010.

${ }^{13}$ Knezevici, D. C., Fuleki, D., Currie, T. C., and MacLeod, J. D. "Particle Size Effects on Ice Crystal Accretion," 4th AIAA Atmospheric and Space Environments Conference, AIAA 2012-3039, 2012.

${ }^{14}$ Van Zante, J. F., and Rosine, B. M. "NASA Glenn Propulsion Systems Lab: 2012 Inaugural Ice Crystal Cloud Calibration," 6th AIAA Atmospheric and Space Environments Conference. American Institute of Aeronautics and Astronautics, 2014.

${ }^{15}$ Addy, H. E., and Veres, J. P. "An Overview of NASA Engine Ice-Crystal Icing Research," NASA/TM-2011$217254,2011$.

${ }^{16}$ Bartkus, T. P., Struk, P. M., and Tsao, J. C. "Development of a Coupled Air and Particle Thermal Model for Engine Icing Test Facilities," SAE 2015 International Conference on Icing of Aircraft, Engines, and Structures Vol. 8, No. 1, 2015. p. 18.

${ }^{17}$ Struk, P. M., Bartkus, T. P., Tsao, J. C., Currie, T., and Fuleki, D. "Ice Accretion Measurements on an Airfoil and Wedge in Mixed-Phase Conditions," SAE 2015 International Conference on Icing of Aircraft, Engines, and Structures, SAE Technical Paper 2015-01-2116, 2015.

${ }^{18}$ Struk, P. M., Bencic, T., Tsao, J., Fuleki, D., and Knezevici, D. C. "Preparation for Scaling Studies of IceCrystal Icing at the NRC Research Altitude Test Facility," 5th AIAA Atmospheric and Space Environments Conference, AIAA-2013-2675 and NASA/TM-2013-216571, 2013. 
${ }^{19}$ Currie, T. C., Struk, P. M., Tsao, J., Fuleki, D., and Knezevici, D. C. "Fundamental Study of Mixed-Phase Icing with Application to Ice Crystal Accretion in Aircraft Jet Engines," 4th Atmospheric and Space Environments Conference, AIAA 2012-3035, 2012.

${ }^{20}$ Vargas, M., Ruggeri, C., Struk, P., Pereira, M., Revilock, D., and Kreeger, R. E. "Ice Particle Impacts on a Flat Plate," SAE 2015 International Conference on Icing of Aircraft, Engines, and Structures, SAE Technical Paper 2015-01-2099, 2015.

${ }^{21}$ Palacios, J., Yan, S., Tan, C., and Kreeger, R. E. "Experimental Measurement of Frozen and Partially Melted Water Droplet Impact Dynamics," 6th AIAA Atmospheric and Space Environments Conference. American Institute of Aeronautics and Astronautics, 2014.

${ }^{22}$ Bartkus, T. P., Struk, P. M., and Tsao, J. "Numerical Analysis of Mixed-Phase Icing Cloud Simulations in the NASA Propulsion Systems Laboratory," 8th AIAA Atmospheric and Space Environments Conference, AIAA Aviation and Aeronautics Forum and Exposition 2016, American Institute of Aeronautcs and Astronautics, Washington, D.C. (submitted for publication).

${ }^{23}$ Wright, W. B., Jorgenson, P. C. E., and Veres, J. P. "Mixed Phase Modeling in GlennICE with Application to Engine Icing," AIAA Atmospheric and Space Environments Conference, AIAA-2010-7674, AIAA $2010-7674,2010$.

${ }^{24}$ Wright, W., Struk, P., Bartkus, T. P., and Addy, G. "Recent Advances in the LEWICE Icing Model," SAE 2015 International Conference on Icing of Aircraft, Engines, and Structures SAE Technical Paper 2015-01-2094, 2015.

${ }^{25}$ Tsao, J., Struk, P. M., and Oliver, M. J. "Possible Mechanisms for Turbofan Engine Ice Crystal Icing at High Altitude," 6th AIAA Atmospheric and Space Environments Conference, AIAA-2014-3044, 2014.

${ }^{26}$ Van Zante, J. F., Ide, R. F., Steen, L. E., and Acosta, W. J. "NASA Glenn Icing Resarch Tunnel: 2014 Cloud Calibration Procedure and Results," NASA/TM-2014-218392, 2014.

${ }^{27}$ Lilie, L., Emery, E., Strapp, J. W., and Emery, J. "A Multiwire Hot-Wire Device for Measurment of Icing Severity, Total Water Content, Liquid Water Content, and Droplet Diameter " 43rd AIAA Aerospace Sciences Meeting and Exhibit, AIAA-2005-859, 2005.

${ }^{28}$ Knezevici, D. C., Fuleki, D., and MacLeod, J. "Development and Commissioning of the Linear Compressor Cascade Rig for Ice Crystal Research," International Conference on Aircraft and Engine Icing and Ground Deicing, SAE Technical Paper 2011-38-0079, 2011.

${ }^{29}$ Struk, P. M., Bartkus, T. P., and Tsao, J. "A Method to Interpret Mixed-Phase Measurements using the SEA Multi-Wire Probe in Select Icing Test Facilities," International Conference on Icing of Aircraft, Engines, and Structures, SAE Technical Paper 15ICE-0036, 2015.

${ }^{30}$ Soeder, R. H. "NASA Lewis Propulsion Systems Laboratory Customer Guide Manual," NASA-TM-106569, 1994.

${ }^{31}$ Veres, J. P., Jorgenson, P. C. E., Wright, W. B., and Struk, P. M. "A Model to Assess the Risk of Ice Accretion due to Ice Crystal Ingestion in a Turbofan Engine and its Effects on Performance," 4th Atmospheric and Space Environments Conference, AIAA 2012-3038, 2012. 